\title{
CITIES AND SMOKING
}

\author{
Michael Darden \\ Working Paper 27334 \\ http://www.nber.org/papers/w27334 \\ NATIONAL BUREAU OF ECONOMIC RESEARCH \\ 1050 Massachusetts Avenue \\ Cambridge, MA 02138 \\ June 2020
}

I thank Matthew Kahn, Christopher Cronin, Yaa Akosa Antwi, and Andrew Friedson for helpful conversations. Data used in preparation of this manuscript are from the National Longitudinal Surveys, Bureau of Labor Statistics and the American Nonsmokers' Rights Foundation. I report no conflicts of interest. No funding was received for this work. The views expressed herein are those of the author and do not necessarily reflect the views of the National Bureau of Economic Research.

NBER working papers are circulated for discussion and comment purposes. They have not been peer-reviewed or been subject to the review by the NBER Board of Directors that accompanies official NBER publications.

(C) 2020 by Michael Darden. All rights reserved. Short sections of text, not to exceed two paragraphs, may be quoted without explicit permission provided that full credit, including () notice, is given to the source. 
Cities and Smoking

Michael Darden

NBER Working Paper No. 27334

June 2020

JEL No. H2,I12

\begin{abstract}
$\underline{\text { ABSTRACT }}$
In $1956,52 \%$ of urban men and $42 \%$ of rural men smoked cigarettes. By 2010 , the disparity had flipped: $24.7 \%$ of urban men and $30.6 \%$ of rural men smoked. Smoking remains the greatest preventable cause of mortality in the United States, and understanding the underlying causes of place-specific differences in behavior is crucial for policy aimed at reducing regional inequality. Using geocoded data from the National Longitudinal Survey of Youth, I estimate a dynamic model that captures smoking behavior, location decisions, and education over thirty years. Simulation of the estimated model demonstrates that selection on permanent unobserved variables that are correlated with smoking cessation, both in native populations and in those who migrate between rural and urban areas, explains $62.8 \$ 1 \% \$$ of the urban/rural smoking disparity. Alternatively, differential tobacco control policies explain only $7.3 \%$ of the urban/rural smoking disparity, which suggests that equalizing cigarette taxes across regions may fail to bridge gaps in behavior and health. This paper emphasizes that rural smoking disparities are largely driven by who selects into rural communities.
\end{abstract}

Michael Darden

Carey School of Business

Johns Hopkins University

100 International Dr.

Baltimore, MD 21202

and NBER

mdarden4@jhu.edu

A data appendix is available at http://www.nber.org/data-appendix/w27334 


\section{Introduction}

Where a person lives is increasingly predictive of their health and longevity. For example, Chetty et al. (2016) document significant variation in life expectancy at the commuting zone level and argue that most of this variation is due to lifestyle differences. Chief among these lifestyle behaviors is cigarette smoking, which is the largest preventable cause of death in the United States and which is increasingly isolated regionally (HHS, 2014). In 1956, 52\% of men living in urban areas and $42 \%$ of men living in rural areas smoked cigarettes (Haenszel et al. , 1956), yet by 2010, while the prevalence of smoking was dramatically lower for both groups, the disparity had flipped: $24.7 \%$ of urban men and $30.6 \%$ of rural men smoked and similar patterns exist for women (American Lung Association, 2012). Rarely do such disparities flip, and understanding how and why such changes occur is important when considering policies aimed at reducing inequality, especially given the well-known longevity (Doll et al. , 2004; Darden et al. , 2018) and health care (Xu et al. , 2015) costs associated with smoking. ${ }^{1}$

In this paper, I study the urban/rural smoking disparity with geocoded data from the National Longitudinal Survey of Youth, 1979 Cohort (NLSY). These data include 30 years of longitudinal information on smoking behavior, county of residence, and education for a cohort of individuals who were between 14 and 22 years of age in 1979 . Longitudinal information on a single cohort is important for the study of cross-sectional disparities because the fractions of populations smoking may change due to a variety of factors that shift either the number of smokers or the general level of population, or both. I classify an individual's county of residence as either metropolitan (metro) or nonmetropolitan (nonmetro) based on criteria from the Rural Urban Continuum Codes (Beale Codes) produced by the United States Department of Agriculture, and I further delineate nonmetropolitan counties by whether they are adjacent to a metropolitan county (adjacent or remote). ${ }^{2}$ In 1984, when the NLSY cohort was between 19 and 27 years of age, smoking prevalence was statistically identical across urban and rural counties; by 2014, the prevalence of smoking was 9.2 percentage points higher in rural counties. The goal of this paper is understand why this gap emerged.

One possibility is that place-based policy differences, which Finkelstein et al. (2019) demonstrate contribute significantly to the cross-sectional variation in life expectancy, have generated differences in smoking prevalence. For example, while state plus local (county and municipal) cigarette taxes were very similar in 1984 , a $\$ 0.57$ (in 2014 dollars) gap emerged by 2014 between urban and rural counties. ${ }^{3}$ Taken together, trends in smoking and

\footnotetext{
${ }^{1}$ For example, regional concentrations of cigarette smoking may explain differences in rates of cancer and cancer mortality (Zahnd et al. , 2018).

${ }^{2}$ There exist a variety of definitions for urban and rural, which makes summarizing the literature on "urban" versus "rural" differences challenging. In what follows, I use the term urban to reflect metropolitan counties and rural to reflect remote counties (i.e., those not immediately adjacent to metropolitan counties). These classifications are formally defined in Section 3.

${ }^{3}$ Author's calculations using cigarette tax information from the American Nonsmokers' Rights Foundation and Orzechowski \& Walker (2017).
} 
cigarette taxes are generally consistent with a story in which local area tobacco control policies have caused the urban/rural smoking disparity. Indeed, a growing public health literature advocates federal tobacco control policies that compensate for state and local areas that "lack the resources or political will to implement and enforce local policies that decrease initiation and increase cessation" (Doogan et al. , 2017). ${ }^{4}$

What remains unclear is whether differential tobacco control policies have caused differences in smoking prevalence or whether changes in attitudes towards cigarettes, which translate into tobacco control laws such as higher cigarette taxes, generated such differences. To the extent that agglomeration economies exist because urban proximity enables ideas to translate into faster human capital accumulation (Glaeser \& Gottlieb, 2009), urban smokers may quit smoking at higher rates because the health consequences of smoking are more salient or because greater human capital implies a larger cost to reduced health and longevity (Grossman, 1972). For example, the slow diffusion of understanding about the health risks of smoking during the latter half of the twentieth century connected faster with more educated smokers (de Walque, 2010), which may have generated regional smoking disparities to the extent that, on average, urban populations are of higher education. If such selection explains the urban/rural smoking disparity, then policymakers should recognize that seemingly successful initiatives to reduce smoking in urban areas may not be as successful in rural areas. Furthermore, urban and rural populations are not static, and observed and/or unobserved traits that drive net migration to urban areas may be negatively correlated with smoking. For example, skill-selected migration (Roy, 1951; Borjas \& Trejo, 1992) may change local area smoking prevalence to the extent that smoking is correlated with skill and skilled workers migrate to high returns to skill urban areas. ${ }^{5}$ Indeed, Borjas et al. (2018) demonstrate that Danish emigrants are positively selected both on (observed) earnings and (unobserved) ability; if either of these characteristics are correlated with smoking behavior, then migration patterns may shift smoking prevalence within local areas.

To evaluate mechanisms behind regional smoking disparities, I estimate a dynamic system of equations model that captures smoking behavior, location decisions, and education over thirty years. Error terms that dictate all behaviors are allowed to be correlated, and I discretize their joint distribution in a semi-parametric way. ${ }^{6}$ Furthermore, I allow an individual's age 14 residence in an urban or rural county to affect the individual-level distribution of unobserved heterogeneity. ${ }^{7}$ Thus, I identify correlation in the propensity to smoke and to live in an urban area from an age when smoking behavior is being formulated, while still allowing for the impact of observed characteristics such as

\footnotetext{
${ }^{4}$ Using data from the National Survey on Drug Use and Health, Doogan et al. (2017) demonstrate that the gap between urban and rural smoking has been widening, largely due to the relatively flat trend in rural smoking from 2007 to 2014 .

${ }^{5}$ Consistent with this theory, Boustan et al. (2013) show that, between 1950 and 2010, the share of the United States population living in an urban area increased from roughly $60 \%$ to $80 \%$, primarily due to a considerable increase in the urban skilled-wage premium.

${ }^{6}$ See Gilleskie et al. (2017) and Darden et al. (2018) for recent examples. The treatment of unobserved heterogeneity follows from Heckman \& Singer (1984) and Mroz (1999), who employ a semi-parametric discrete factor approach.

${ }^{7}$ See Keane \& Wolpin (1997) for the first example of using initial conditions data to shift an unobserved factor. See Arcidiacono et al. (2007) for a structural example in a model of risky behaviors.
} 
education. The estimated model allows me to simulate how the distribution of observed and unobserved variables shift over time and across space. Identification of the model comes from rich data on local area characteristics, including "push" variables that characterize local labor markets and tobacco control and prevalence measures at the county/municipal level that may induce smoking cessation.

Over the age distribution, smoking prevalence peaks in the early twenties, when, in this cohort, urban and rural areas see similar levels of smoking. I find that urban smoking prevalence drops much faster as individuals age, both because of net sorting of non-smokers to urban areas and because the types of individuals remaining in rural areas have stronger preferences for cigarettes. While the share of rural residents declines only slightly over the 30-year period, the share of those rural residents especially unlikely to smoke declines by $7.3 \%$, as measured by the shifting distribution of unobserved heterogeneity. A simulation of the estimated model in which I equalize the distribution of unobserved permanent heterogeneity at age 14 across space and restrict migration such that the compositions of urban and rural areas do not change explains $62.8 \%$ of the urban/rural smoking disparity. On the other hand, after conditioning on observed and unobserved heterogeneity, I find limited evidence that differential tobacco control laws have generated smoking disparities. A simulation in which I assign the mean urban tobacco control laws in each year to anyone selecting a rural location reduces the 2014 urban/rural smoking disparity by only $7.3 \%$. These results suggest that selection on observed and unobserved factors correlated with smoking explain most of the smoking disparities across space, and they are robust to a variety of modeling choices, including using survey weights and different models of unobserved heterogeneity.

Taken together, the results from reduced-form and quasi-structural models suggest a limited causal role for urban tobacco control policies. In fact, over the long-run, tobacco control policies are themselves selected: these endogenous local area measures reflect urban smoking attitudes, which may have evolved differently as the compositions of urban areas evolved. Instead, those raised in urban areas are less likely to continue smoking and more likely to remain in urban areas and seek higher education. Individuals mismatched to their location at young ages migrate, but these individuals constitute a small fraction of the sample. These results suggest that expanding existing tobacco control policies in rural areas would have only a modest effect on smoking disparities, consistent with recent evidence that rural communities are less supportive of indoor smoking restrictions (Stillman et al. , 2018).

\section{Background and Theory: Selective Migration as a Mechanism}

This paper contributes to a significant literature on regional inequality. For example, Autor (2019) finds that urban workers without a college degree have seen dramatic decreases in the skill required at work, largely due to automation and globalization. That paper argues that urban wage-premia no longer exist for relatively low skilled workers, which 
is consistent with Ganong \& Shoag (2017), who document migration of low-educated individuals away from high returns-to-skill areas. If these migrants are more likely to be smokers, then smoking prevalence may increase in rural areas simply by migration. Importantly, while interstate migration is low in the United States, this literature suggests that net changes in smoking prevalence may be driven both by smokers moving out of urban areas and non-smokers moving out of rural areas. I find that unobserved heterogeneity in the joint determination of smoking, rural location, and low education are strongly correlated.

This paper also contributes to the "brain drain" literature by pointing out that valuable skills, and their empirical proxies such as education and test scores, are correlated with a wide variety of behaviors and outcomes whose compositions within local areas may also change with migration, even if these factors do not directly cause migration. The brain drain theory says that skill-selected migration causes low returns-to-skill source locations to lose highly skilled workers (and potentially gain low-skilled migrants), decreasing the skill composition of the local workforce. ${ }^{8}$ At the same time, migrants selected on skill may also shift the political, economic, health, and social compositions of local areas. For example, Hillygus et al. (2017) argues that migration away from high-cost urban centers in the northeast may substantially shift the political composition of states in the U.S. South. Indeed, Docquier \& Rapoport (2012) argue that skill-based ex post brain drains are becoming an increasingly important feature of 21st century globalization. Yet migration need not be driven by returns to skill. Young (2013) shows that differential skill prices are not needed to generate skill composition shifts if workers select on unobserved individual characteristics that are correlated with education. While I am not claiming that smoking drives migration, there may be factors, skill-based or otherwise, which are correlated with smoking and education and that drive migration. This paper emphasizes that what matters is population composition, both stock and flow.

To exemplify the potential for migration to influence the smoking composition of a local area, I propose a simple model of skill-selected migration following from Roy (1951) and Borjas \& Trejo (1992). The model's value is in demonstrating that migration can shift the relative smoking rate between two areas, the extent of which depends on the correlation between skills and the propensity to smoke, as well as the local area characteristics across regions.

The basic model is of young individuals in two locations, $\mathrm{U}$ and $\mathrm{R}$, where the only input in firms' production functions in both locations is labor. In both locations, workers are paid their marginal product, which is a function of a uni-dimensional measure of skill, $S$. Skill represents both innate ability and those skills which have accumulated through formal investment. In addition to skill, workers are differentiated by their preference for cigarettes $Z$, which captures the total marginal utility of smoking. ${ }^{9}$ As a baseline scenario, suppose that, for individuals in both locations, $S$ and $Z$ are drawn from a common population bivariate normal distribution where the means of both $S$

\footnotetext{
${ }^{8}$ See Kwok \& Leland (1982) and Miyagiwa (1991)

${ }^{9}$ Another interpretation of $Z$ is as the stock of addictive capital (Becker \& Murphy, 1988).
} 
and $Z$ are zero. ${ }^{10}$ Let $\rho$ denote the correlation between $S$ and $Z$.

The model proceeds in two phases: the migration phase and the smoking phase. The migration phase begins immediately following formal skill investment and entrance into the labor market. Upon entering the labor market, each individual receives a wage offer from each location as a function of their skill. Let the wage determination equation in location $j$ be given as:

$$
\ln \left(w^{j}\right)=\theta_{0}^{j}+\theta_{1}^{j} S
$$

Without loss of generality, assume that $\theta_{0}^{U}>\theta_{0}^{R}$ and $\theta_{1}^{U}>\theta_{1}^{R}$. Thus, location $U$ has both a higher return to skill and a higher mean wage. Let $c$ represent the constant and symmetric cost of moving between locations, and let $\pi=\frac{C}{w}$ represent the time-equivalent mobility cost (Borjas, 1987). Assuming that the price of consumption is 1 such that an individual maximizes log income, an individual migrates if the wage offer net of $\pi$ is greater than the wage offer in their initial location. In this setting, a person moves from $\mathrm{R}$ to $\mathrm{U}$ when:

$$
S>\frac{\theta_{0}^{R}-\theta_{0}^{U}+\pi}{\theta_{1}^{U}-\theta_{1}^{R}}=\beta
$$

and a person moves from $\mathrm{U}$ to $\mathrm{R}$ when:

$$
S<\frac{\theta_{0}^{R}-\theta_{0}^{U}-\pi}{\theta_{1}^{U}-\theta_{1}^{R}}=\delta
$$

The decision rules given in Equations 2 and 3 characterize the equilibrium sorting on the basis of skill. As the returns to skill differential, $\theta_{1}^{U}-\theta_{1}^{R}$, increases, the skill threshold for migration from location $R$ to location $U$ decreases. Similarly, because those in $U$ with $S<0$ are penalized by increasing returns to skill, as the returns to skill differential increases, the skill threshold for low skilled individuals in location $U$ to move to $R$ increases. Equations 2 and 3 make clear that, depending on the parameters $\theta$ and $\pi$, migration will cause a shift in the skill composition such that location $U$ contains more highly skilled individuals than location $R$. Furthermore, note that neither $Z$ nor expectations about cigarette prices/policies conditional on $Z$ enter into the migration decision. ${ }^{11}$

Assuming that the propensity to smoke is increasing in $Z$, skill-selected migration will shift smoking prevalence in each location through composition changes in $Z$. Specifically, migrants from $\mathrm{R}$ to $\mathrm{U}$ have a mean addictive stock given as:

$$
E(Z \mid S>\beta)=\rho \sigma_{Z} \lambda(\beta)
$$

\footnotetext{
${ }^{10}$ The normalization of the mean of skill is without loss of generality as skills will generally not be separately identified from the return to skill. The common support assumption is consistent with the fact that urban and rural counties had the same smoking prevalence in 1984 in the NLSY.

${ }^{11}$ Kwok \& Leland (1982) formalize a model of brain drain in which asymmetric information on the part of firms may prevent foreigntrained graduates to return home. Kaplan (2017) argue that the dramatic reduction in temporary internal migration in the United States is because the internet has dramatically reduced uncertainty about a location and its amenities. Here, assuming that migration choices are independent of tobacco control policies is a simplification that is not crucial to the results that follow.
} 
where $\lambda$ is the inverse mills ratio evaluated at the $\mathrm{R}$ to $\mathrm{U}$ migration skill threshold. Assuming a negative correlation between $Z$ and $S$, Equation 4 demonstrates that the average preference for smoking decreases in $U$ and increases in $R$ just from $\mathrm{R}$ to $\mathrm{U}$ migration. Similarly, the expected value of $Z$ for those migrating from $U$ to $R$ is given as:

$$
E(Z \mid S<\delta)=-\rho \sigma_{Z} \frac{\phi(\delta)}{\Phi(\delta)}
$$

Thus, the size of the net flow of smokers in $U$ and $R$ depends on the correlation between skill and the preference for smoking, the variance in smoking preference, and the degree of migration. Importantly, migration can generate smoking disparities even in the case of one-way traffic (e.g., very negative $\delta$ ).

Following sorting, an individual decides whether to smoke cigarettes, which, for simplicity, is limited to the extensive margin of smoking. Define an individual's utility as $V(C, d ; Z, S)$, where $C$ is general consumption, $d$ represents whether or not a person smokes cigarettes, and $Z$ and $S$ potentially shift the marginal utilities of the direct utility arguments. Furthermore, assume that the price of consumption is $\$ 1$ and the total price of cigarettes, inclusive of any location specific taxes, is $p^{j}$. Then, it follows that an individual will smoke if:

$$
V\left(w^{j}-p^{j}, 1 ; Z, S\right)>V\left(w^{j}, 0 ; Z, S\right)
$$

Equation 6 demonstrates the incentives to smoke cigarettes faced by those in each location. Assuming that the marginal utility of smoking is increasing in $Z$, which would capture the addictive mechanisms of reinforcement, tolerance, and withdrawal discussed in Becker \& Murphy (1988) and Darden (2017), a crucial parameter is the correlation between $S$ and $Z$. Prior to the migration phase, $Z$ and $S$ were allowed to be correlated, but individuals in locations $U$ and $R$ drew from the same population joint distribution of $Z$ and $S$. As the migration phase created location specific distributions of $S$, the extent to which the relative distribution of $Z$ changed will depend on the correlation between $Z$ and $S$. If $S$ and $Z$ are negatively correlated, then skill-selected migration will cause high skill, low $Z$ individuals to move from $R$ to $U$, and low skill, high $Z$ individuals to move from $U$ to $R$, changing smoking prevalence in each location.

Location specific tobacco control policies work within the assumed budget constraint by drawing from general consumption. However, if utility is concave in consumption, then tobacco control policies will be less effective for high wage (and thus higher skill) individuals. This issue highlights the difficultly in inferring whether cigarettes are, in fact, a normal good. ${ }^{12}$ Notice that differential tobacco control policies may in fact augment the correlation between skill and preference for cigarettes if location $U$ policymakers enact strong tobacco control laws (which effectively reduce smoking) and net sorting on the basis of skill causes the skill distribution in $U$ to be to the right of that in

\footnotetext{
${ }^{12}$ See Kenkel et al. (2014) for evidence that cigarettes are normal.
} 
$R$. Put differently, as location $U$ has a skill distribution to the right of that of location $R$, relatively large tobacco control policies in $U$ may strengthen the correlation between smoking and skills, to the extent that these policies induce individuals to quit smoking.

In what follows, I use the NLSY 1979 to explore changes in urban versus rural rates of smoking over time and the correlation between proxies for skills and proxies for $Z$. The model makes clear that the composition of local areas is what matters, but the assumption of $S$ and $Z$ being drawn from a common distribution may not hold the NLSY in the sense that baseline skills and smoking preference, which are unobserved, may vary by region. This underscores an initial conditions problem, for which I attempt to correct by both individual fixed effects and random unobserved heterogeneity that is allowed to vary by location at a young age.

\section{Data}

To evaluate the mechanisms driving the urban/rural smoking disparity, I turn to the National Longitudinal Survey of Youth, 1979 Cohort (NLSY). Longitudinal information on a single cohort is important for the study of cross-sectional, long-run disparities because a panel allows me to hold the sample of study fixed. That is, place-specific smoking prevalence will not vary within a balanced panel due to differential rates of, for example, fertility. Furthermore, in a sample of young adults transitioning to adulthood, selected mortality due to smoking is likely to be extremely low (Doll et al. , 2004; Darden et al. , 2018). Geocoded information in the NLSY allow me to identify the county of residence at each interview wave as well as the county of residence when the respondent was 14 years of age. Between 1979 and 2014, information on smoking behavior was recorded in the NLSY at eight waves (1984, 1992, 1994, 1998, 2008, 2010, 2012, and 2014). I construct a balanced panel of individuals over these eight waves, dropping those who miss any of the smoking waves and those who leave the sample through attrition or death. I also restrict the sample to just those with consistent and non-missing location, smoking, and education information. The final estimation sample includes information on 4,626 individuals for 37,008 person/year observations. ${ }^{13}$

There is little agreement on how to define rural counties in the United States. Classification schemes, of which there are dozens used by government entities, usually combine information on county population, proximity to major urban centers, and commuting flows. The most commonly used classification scheme comes from the United States Office of Management and Budget (OMB), which defines counties as either metropolitan (metro) or nonmetropolitan (nonmetro). A metro county includes a labor market with a dense urban area of 50,000 residents or more and which has outlying counties that are economically dependent. Nonmetro counties represent all other counties and are the

\footnotetext{
${ }^{13}$ The decision to focus on a balanced sample is based on implementation of the system of equations model later in the paper. Appendix Table A1 presents details on sample construction.
} 
traditional definition of rural counties in most economic and public health research. ${ }^{14}$ To further refine metro and nonmetro counties, the United States Department of Agriculture Economic Research Service (USDA ERS) produces the Rural-Urban Continuum Code, also known as the Beale Code, which is a number between one and nine that classifies a county on both the urban population within the county as well as the county's proximity to a metropolitan county. ${ }^{15}$ The advantage of the Beale Code is that it includes the standard metro/nonmetro distinction used by OMB - codes one through three are defined as metro counties, and codes four through nine are defined as nonmetro counties - yet it also provides a more granular definition within metro and nonmetro counties. ${ }^{16}$ Within a given classification scheme, there is also little consensus across the literature in how to subcategorize counties. For example, Doogan et al. (2017) defines rural counties as those counties with a Beale Code of 8 or 9, whereas Singh \& Siahpush (2014) defines 5 categories: large metro, medium metro, small metro, urban nonmetro, and rural nonmetro. ${ }^{17}$ This lack of uniformity makes comparisons of "rural" disparities across behaviors and outcomes difficult.

In this paper, I merge the 2013 Rural-Urban Continuum Code (Beale Code) to NLSY 1979 data, and I define counties based on "remoteness," representing a scheme most closely related to that in Winkler \& Johnson (2016), who study migration and ethnoracial segregation. To the extent that attitudes and information with respect to smoking and health proliferate within metro counties, these ideas may spill over to adjacent counties that are economically dependent. Rather than model migration into and out of 9 classifications, for this paper, I define three categories of counties: metro, adjacent, and remote. Metro counties are those counties with a Beale Code of less than 4. Adjacent counties are nonmetro counties of various populations which are adjacent to counties classified as metro (Beale Codes 4, 6, and 8). Remote counties are both nonmetro counties and non-adjacent to any metro county (Beale Codes 5 , 7, and 9). This classification of rural counties is relatively fine, whereas the standard definition of a rural county is simply as a nonmetro county (i.e., Beale Code $>3$ ). By focusing on counties that are not adjacent to metro counties, the interpretation of rural in this paper is consistent with relatively remote areas. While I present statistics for both metro versus nonmetro (i.e., metro relative to adjacent plus remote disparities), the main object of interest in this paper is the metro/remote disparity, which is largest in magnitude. ${ }^{18}$

Beale Code updates are available in 1983, 1993, 2003, and 2013 based on the preceding Census, but for two reasons I classify counties based only on the 2013 update. First, USDA significantly changed the methodology for identifying "metro" counties in 2000, and updates in years 2003 and 2013 are not comparable with those in 1983

\footnotetext{
${ }^{14}$ See Coughlin et al. (2019), Cepeda-Benito et al. (2018), and Zahnd et al. (2018) for examples. See https://www.ers.usda.gov/topics/rural-economy-population/rural-classifications/what-is-rural/ for a complete description.

${ }^{15}$ See https://www.ers.usda.gov/data-products/rural-urban-continuum-codes.aspx. Accessed on January 8th, 2020. Appendix Table A2 lists the 2013 Beale Code classifications.

${ }^{16}$ Alternatives to the Beale Code that are also produced by USDA ERS include Urban Influence Codes and Rural-Urban Commuting Area Codes. Furthermore, the National Center for Health Statistics (NCHS) uses a completely different classification scheme (Ingram \& Franco, 2014).

${ }^{17}$ Hales et al. (2018) and Hall et al. (2019) use the NCHS classification scheme to define urban, small-metro, and rural counties.

${ }^{18}$ Throughout the paper, I use the terms urban and metro, and rural and remote, interchangeably.
} 
and 1993. ${ }^{19}$ Second, with time-varying classifications for metro, adjacent, and remote counties, an NLSY individual could transit between categories without moving, and it is not clear how the smoking behavior should differ between someone who actively moves to an metro area versus someone who never moves but lives in a county that urbanizes. While in principle this variation could be exploited within a model of migration, the first limitation renders the point mute. Using only 2013 Beale Code information introduces measurement error in the sense that counties that urbanized quickly will be misrepresented in early waves of the NLSY; however, this paper is ultimately concerned with the trajectory of the smoking disparity into the present, and the 2013 Beale Code correctly captures recent trends. Using the 1983 Beale Code to classify counties results in a much smaller disparity in 2014, which is to be expected as many counties that have urbanized and which may have lower smoking prevalence are incorrectly classified as rural.

\section{Figure 1 Goes Here}

Figures $1 \mathrm{a}$ and $1 \mathrm{~b}$ show predicted smoking prevalence by county classification from a linear probability model of whether an NLSY 1979 respondent smokes. The model interacts county of residence classification with year binary variables, where metro counties are the omitted category, and confidence bands represent the $95 \%$ confidence intervals on the coefficients that capture deviations from the metro county smoking trend. Figure 1a shows that smoking prevalence was equivalent in the NLSY 1979 cohort in 1984 between metro and nonmetro counties. By 2014, a statistically significant gap of 4.3 percentage points emerged between metro and nonmetro counties. Figure $1 \mathrm{~b}$ presents the same type of information, except nonmetro counties are separated in to adjacent (Beale Code $\in\{4,6,8\}$ ) and remote (Beale Code $\in\{5,7,9\}$ ) counties. The figure demonstrates that most of the difference in smoking prevalence in Figure 1a is driven by remote counties, where the 2014 gap of remote relative to metro counties is 9.2 percentage points. Figures 1c and 1d provide suggestive evidence of the role of cigarette taxes. Each figure presents the predicted state plus local (county and municipal) cigarette tax rates by county classification in 2014 dollars. Both pictures show a roughly $\$ 0.55$ gap emerging, but Figure $1 \mathrm{~d}$ shows that while adjacent and remote counties saw similar increases in taxes through 2014 - it was metro county taxes that increased at a much faster rate. As I discuss below, Figure 1d demonstrates the importance of local cigarette tax data - between 1984 and 2014, many metro areas enacted significant increases in cigarette taxes.

To the NLSY and Beale Code data, I merge county level labor market and education information from Carneiro et al. (2012), who model the intergenerational effects of maternal education on children's outcomes in the NLSY. ${ }^{20}$

\footnotetext{
${ }^{19}$ The two leading alternatives to the Beale Code - the National Center for Health Statistics code and the United States Department of Agriculture Urban Influence codes - are also not comparable over time.

${ }^{20} \mathrm{I}$ use the data shared in the supplemental data section of Carneiro et al. (2012).
} 
These data include county level information on the local labor market unemployment rate and mean log hourly wage. The data also include information on whether there is a four-year college in the county of residence at age 14 and the state of residence mean of four-year and two-year college tuition. Importantly, data are available between 1974 through 1981, which allows for merging at the county level when the respondent was 17-years of age in the county of residence at age 14. Carneiro et al. (2012) cite a large literature that use these variables as exogenous shift variables of the probability of higher education for individuals in the NLSY. Additionally, using data from Orzechowski \& Walker (2017) and the American Nonsmokers' Rights Foundation, I merge municipal/county/state/year level cigarette excise tax information. ${ }^{21}$ These data richly characterize the local area cigarette tax exposure, and they represent a clear improvement over using only state level variation. Indeed, real, metro local area cigarette taxes increased over six-fold from 1984 to 2014, whereas the mean local cigarette tax in remote counties remained less than one cent in 2014. In addition to local area level cigarette tax information, I merge state information on the gross tax revenue from cigarettes, the mean number of cigarette pack sales per capita, and the state cigarette excise tax at the state/year level from Orzechowski \& Walker (2017). All dollar figures are in 2014 dollars. To summarize, the data contain longitudinal information on a cohort of individuals from 1984 to 2014, including rich information on the local labor market and tobacco regulatory environment at the county/state level.

\section{Table 1 Goes Here}

Table 1 presents summary statistics of the data by location aggregated over the entire panel. ${ }^{22}$ Of the 37,008 person/year observations, roughly $5.2 \%$ are of individuals in remote areas. Those remote observations have higher rates of smoking relative to adjacent and metro areas ( 0.299 vs. 0.259 and 0.231 , respectively), but are not significantly different with respect to age or gender. The fraction of Hispanic and African-American individuals are significantly higher in metro areas, as is the fraction of individuals with a college degree or more. Despite having fewer smokers, metro areas generate significantly more cigarette tax revenue, which demonstrates the difference in tobacco control policies by region. Furthermore, significantly more cigarettes are sold per capita in remote areas, which suggests that remote areas have different attitudes towards smoking.

To evaluate the metro/remote smoking disparity, I begin by estimating a series of regressions that progressively

\footnotetext{
${ }^{21}$ I merge individuals by county of residence to cigarette tax changes at the county level regardless of whether the legislation is at the county or municipal level.

${ }^{22}$ Throughout the paper, reported statistics and estimates are unweighted because the sample restrictions required to generate a balanced panel limit the usefulness of survey weights. A concern may be that, because NLSY oversamples minorities, failing to weight observations may place undue weight on groups that are less likely to smoke. However, none of metro/remote smoking disparity is explained by the ethnic composition of different regions, and my results are not sensitive to including survey weights as controls. These results are available by request.
} 
control for additional potentially confounding variables. Specifically, I estimate versions of Equation 7:

$$
\begin{aligned}
\text { Smoke }_{i t}=\sum_{t=2}^{8} \alpha_{0 t} 1[\text { Wave }=t] & +\sum_{t=1}^{8} \alpha_{1 t} 1[\text { Wave }=t] 1\left[\text { Adjacent }_{i t}=1\right]+ \\
& +\sum_{t=1}^{8} \alpha_{2 t} 1[\text { Wave }=t] 1\left[\text { Remote }_{i t}=1\right]+x_{i t} \beta+\epsilon_{i t}
\end{aligned}
$$

where the $\alpha_{0 t}$ parameters reflect the metro trend in smoking and $\alpha_{1 t}$ and $\alpha_{2 t}$ parameters represent deviations from trend for those living in adjacent and remote areas, respectively. The sums are over the eight waves of the NLSY that asked about smoking behavior (1984, 1992, 1994, 1998, 2008, 2010, 2012, and 2014), and the omitted wave category is metro residents in 1984. In Equation 7, $x_{i t}$ represents a vector of control variables. Figure $1 \mathrm{~b}$ demonstrates trends in smoking prevalence over the eight waves without controls (i.e., $\beta=0 \forall x$ ), with $95 \%$ confidence intervals presented on the $\alpha_{2 t}$ parameters. $^{23}$ In 1984, when respondents were between the ages of 19 to 27 , there was no significant difference, economically or statistically, between predicted smoking prevalence in metro and remote counties. By 2014, a roughly 9.2 percentage point difference emerged between metro and remote counties, as rates of smoking in metro counties declined much faster. The p-value of on the F-test that all wave-remote county coefficients are zero is 0.01 .

\section{TABle 2 Goes Here}

Table 2 presents estimates of the $\alpha_{2 t}$ parameters while progressively controlling for more potential confounding variables. Throughout, standard errors are clustered at the individual level. Column 1 of Table 2 presents the remote deviations from the metro trend that are used to construct Figure 1b. Columns 2 and 3 demonstrate that the remote deviations from trend are largely unaffected by controls for age, gender, and race. Column 4 includes controls for the highest level of completed education. Remote deviation estimates in column 4 are significantly smaller than those in previous columns, suggesting that differences in the education composition of remote areas are important in the metro/remote smoking disparity, however the deviation in 2014 of 6.1 percentage points remains meaningful, as does the 6.2 percentage point difference presented in column 5 after controlling for AFQT score, measured in 1981, and local area tobacco control policies. Finally, column 6 presents estimates of the $\alpha_{2 t}$ parameter from an individual fixed effects model, with all other time invariant controls dropping out. The 2014 remote deviation from trend remains statistically significant and large at 7.4 percentage points in 2014 .

Column 6 of Table 2 isolates within individual variation in smoking and location and is identified off of those individuals who move between metro, adjacent, and remote areas. Glaeser \& Mare (2001) demonstrate that those

\footnotetext{
${ }^{23}$ The Figure omits adjacent smoking estimates for ease of presentation.
} 
migrating to urban areas do not immediately enjoy a metro wage premium, but they do enjoy faster wage growth, which suggests a causal role for cities in generating productivity. To the extent that such productivity gains imply increased awareness (or increased opportunity costs) of the health consequences of smoking, we would expect smoking prevalence to gradually decline following migration from remote to metro areas. For example, smokers moving from remote to metro areas may continue smoking initially but later quit because of higher metro cigarette taxes or because the per capita rate of smoking is lower and smoking is more socially isolating. To investigate the possibility for such patterns, I estimate a series of event study specifications that capture how smoking evolves before and after different types of migration.

$$
\begin{array}{r}
\text { Smoke }_{i t}=\sum_{t=2}^{8} \alpha_{0 t} 1[\text { Wave }=t]+\sum_{j=-5}^{-2} \phi_{(j+6)} 1[\text { Moved in wave } \mathrm{t}+\mathrm{j}] \\
+\phi_{6} 1[\text { Moved in wave } \mathrm{t}]+\phi_{7} 1[\text { Moved in wave } \mathrm{t}-1]+ \\
+\phi_{8} 1[\text { Moved } 2 \text { or waves prior to } \mathrm{t}]+x_{i t} \beta+\mu_{i}+\epsilon_{i t}
\end{array}
$$

Equation 8 presents the event study specification. Here, in addition to wave dummies $\left(\alpha_{0}\right)$ and individual fixed effects $\left(\mu_{i}\right)$, I capture differential effects on smoking for the five periods prior to a move, where the period just prior to the move is normalized to zero (i.e., $\phi_{5}=0$ ), and the effects immediately after, one period after, and two or more periods after a move. ${ }^{24}$

\section{Figure 2 Goes Here}

Figure 2 plots estimates of the $\phi$ parameters for various types of moves, including a move across states (a), across counties (b), from a metro to remote county (c), and from a remote to metro county (d). In all four cases, Figure 2 demonstrates no significant change in the smoking behavior of migrants and no significant differential trends prior to migration - smokers do not select into migration after controlling for individual fixed effects. This last point is important, as fixed effects help to equalize pre-migration trends, they may also mask selected migration.

Estimates from Table 2 and Figure 2 demonstrate that selection on observables and unobservables can explain a significant fraction of the metro/remote smoking disparity, yet for three reasons the results are unsatisfying. First, Equation 7 assumes that whether someone lives in a remote area is exogenous conditional on $X$. As a result, in the absence of exogenous variation in migration, much of the empirical literature that has flowed from the Roy model has been descriptive. ${ }^{25}$ Second, smoking is highly addictive, and Equations 7 and 8 ignore these dynamics

\footnotetext{
${ }^{24}$ Because time between waves varies significantly, it is important to control for both wave dummies and age.

${ }^{25}$ See Molloy et al. (2011), Kaplan (2017), Johnson \& Schulhfer-Wohl (2019), among many others.
} 
in favor of incorporating individual fixed effects. Finally, individual fixed effects ignore important cross-sectional variation such as education and observed ability (AFQT), which potentially have an important and policy relevant role in explaining the metro/remote smoking disparity. For these reasons, I put more structure on the problem by estimating and simulating a dynamic system of equations model of education, smoking, and migration that flexibly handles permanent unobserved heterogeneity. ${ }^{26}$

\section{Dynamic Empirical Model}

The goal is to develop a framework that allows for a.) dynamics in smoking and location decisions, b.) initial conditions outcomes for location, smoking, and education, and c.) unobserved heterogeneity. I estimate the parameters of each equation jointly via full-information maximum likelihood, which allows for the characterization of correlation in the error structures of each equation. The model follows from several papers that use similar "quasi-structural" approaches to dynamic questions - that is, the model allows for simultaneity and dynamic behavior without imposing full-solution of a dynamic optimization problem (Darden et al. , 2018; Gilleskie et al. , 2017; Mroz, 1999). The framework derives from an intertemporal model of choice, in which an individual maximizes the lifetime present discounted value of utility in each of $T$ waves. Rather than solve this problem explicitly, the empirical framework of this paper recognizes that solution to such a model would generate demand equations for cigarettes and for location of residence. ${ }^{27}$ The empirical implementation presented below estimates a demand for smoking and a demand for migration equation which represent the reduced-form of a more elaborate model. These demand equations are functions of a state space which captures past decisions and outcomes. The point is that the dynamic system is sufficient to study the relative mechanisms driving smoking disparities.

\section{Figure 3 Goes Here}

Figure 3 demonstrates how the model is specified over the NLSY sample period. At the left, the NLSY contains information about the county of residence at age 14, which would have occurred between 1971 and 1979. Whether or not someone lives in a remote county at this age is endogenous and represents a standard initial conditions problem. Following Keane \& Wolpin (1997), I allow residence at age 14 to affect a permanent unobserved factor $\mu_{i}$. As $\mu_{i}$ will enter each subsequent equation in the model, it's distribution is unlikely to be multivariate normal; thus, I discretize

\footnotetext{
${ }^{26}$ This approach is in the spirit of Kennen \& Walker (2011), who estimate a dynamic structural model of interstate migration using the NLSY79 data and conclude that expected earnings play a key role in location decisions.

${ }^{27}$ Within that larger model, an individual would receive a wage draw in every wave that represents an employment offer from each location.
} 
the distribution of $\mu_{i}$ by assuming that $\mu_{i}$ takes one of three values, with the first normalized to zero: $\left\{0, \mu_{2}, \mu_{3}\right\} .^{28}$ For example, an individual represented by $\mu_{3}$ would receive the $\mu_{3}$ value in each subsequent equation, where each value of $\mu_{3}$ is estimated and differs across equations. The probability of each type is individual specific according to the following multinomial logit:

$$
P\left(\mu=\mu_{j}\right)=\frac{\exp \left(\psi_{1 j} 1\left[\text { Adjacent }_{\text {age }=14}=1\right]+\psi_{2 j} 1\left[\text { Remote }_{\text {age }=14}=1\right]\right)}{\sum_{k=1}^{3} \exp \left(\psi_{1 k} 1\left[\text { Adjacent }_{\text {age }=14}=1\right]+\psi_{2 k} 1\left[\text { Remote }_{\text {age }=14}=1\right]\right)}
$$

Starting in the first wave with smoking information in 1984, I estimate time invariant equations that capture an individual's highest level of education, whether they live in a metro, adjacent, or remote area, and whether they smoke. These equations are:

$$
\begin{gathered}
p\left(e_{i}=e\right)=e\left(X_{i, 1984}, M_{i, a g e=17}, \mu_{i}^{e}, \epsilon_{i}^{e}\right) \\
p\left(m_{t=1984}^{\prime}=m^{\prime}\right)=m\left(X_{i, 1984}, e_{i}, \mu_{i}^{m^{\prime}}, \epsilon_{i}^{m^{\prime}}\right) \\
p\left(s_{i}=s\right)=s\left(X_{i, 1984}, e_{i}, P_{a g e=14}, \mu_{i}^{s^{\prime}}, \epsilon_{i}^{s^{\prime}}\right)
\end{gathered}
$$

Equation 10 is a multinomial logit for education categories 1 through 4, representing less than high school, high school graduate, some college, or college graduate or more, respectively. ${ }^{29}$ The omitted category is less than high school. Importantly, Equation 10 includes county level education supply factors $M$, including the presence of a university within the county and state 4-year college tuition averages, which are measured when the individual was 17 years of age in their county of residence at age 14. Figure 3 demonstrates that age 17 education variables are realized prior to $1984 .^{30}$

Equation 11 is a multinomial logit for location in 1984, with metro as the omitted category. Location is a function of education, which allows for school-related migration. Equation 12 is a logit for whether person $i$ smokes in 1984 . Smoking is a function of a vector of tobacco control policies in their state and county of residence when the person was 14 years of age. Specifically, the state and county/municipal cigarette tax and their squares are included, as well as, measures that capture the prevalence of smoking in a person's state of residence, including the pack sales per capita and the gross tax revenue from cigarettes. The assumption is that these age 14 tobacco control laws and prevalence measures predict smoking initiation (see Appendix Table A5), but they only affect subsequent smoking and location decision through smoking observed in 1984.

\footnotetext{
${ }^{28}$ This follows from a standard discrete factor method for unobserved heterogeneity. See Heckman \& Singer (1984) and Mroz (1999). Points of support are added until the log-likelihood function value does not significantly improve.

${ }^{29}$ By 1984, most individuals in the NLSY had achieved their highest level of education. For those still enrolled in school in $1984, e_{i}$ still reflects their highest level of schooling over the entire sample wave.

${ }^{30}$ This limitation of the data introduces measurement error in the sense that age 17 variables are merged to the county of residence at age 14 .
} 
For subsequent NLSY waves, I model the per-wave location and smoking decisions. The timing of the model is assumed to be such that an individual chooses whether to live in a metro, adjacent, or remote county, followed by whether to smoke conditional on location. This timing assumption is made to reflect the timing of the data as well as the fact that smoking decisions should be a function of current local area tobacco control policies. ${ }^{31}$ Thus, in wave $t$, the location decision is given as:

$$
p\left(m_{i t}=m\right)=m\left(X_{i t}, E_{i}, m_{i t-1}, S_{i t-1}, L_{i t-1}, \mu_{i}^{m}, \epsilon_{i t}^{m}\right)
$$

where $m \in\{$ Metro, Adjacent, Remote $\} . X_{i t}$ represents exogenous characteristics, $E_{i t}$ represents a person's highest level of education, and $m_{i t-1}$ and $S_{i t-1}$ represent lagged location and smoking variables. $L_{i t-1}$ represents lagged local area characteristics that may "push" an individual to migrate, such as the county level unemployment rate. As in Equations 10-12, $\mu^{m}$ and $\epsilon_{i t}^{m}$ represent the unobserved portion of the migration equation, where $\mu^{m}$ is a permanent unobservable characteristic that is correlated across each equation in the model and $\epsilon_{i t}$ is an i.i.d. error across individuals and time disturbance. Under the assumption that $\epsilon_{i t}$ takes an extreme value, type 1 distribution, Equation 13 is a multinomial logit equation, where metro is the omitted category.

Following the location decision, an individual decides whether to smoke cigarettes. The probability of smoking is given as:

$$
p\left(s_{i t}=s\right)=s\left(S_{i t-1}, X_{i t}, E_{i}, P_{i t}, \mu_{i}^{s}, \epsilon_{i t}^{s}\right)
$$

where the right-hand side is differentiated from Equation 13 by $P_{i t}$, the wave $t$ tobacco control policies to which individual $i$ is exposed. Also included in $P_{i t}$ are smoking prevalence measures that roughly proxy for population-level attitudes towards smoking, including annual pack sales per capita and annual gross tax revenue from cigarettes. The smoking equation is a function of lagged smoking, which captures persistence due to addiction. The unobserved part of the right hand side is similar to that in Equation 13, but the superscript $s$ denotes that realizations of each term are different. By modeling unobserved heterogeneity in this way, the model can consistently account for both dynamics, through $S_{i t-1}$, and unobserved heterogeneity, through $\mu_{i}^{s}$. Equation 14 represents a binary logit for smoking.

Subject to distributional assumptions that each of the $\epsilon$ terms follow an i.i.d. type 1 extreme value error, each equation represents a logit equation. I use full-information maximum likelihood to estimate the model parameters. To integrate out the unobserved factor $\mu$, the likelihood function takes the form of a weighted average of each

\footnotetext{
${ }^{31}$ The timing also assumes that no one moves because of tobacco control policies.
} 
individual's contribution conditional on $\mu$ type. Specifically, person $i^{\prime} s$ contribution to the likelihood function is:

$$
\begin{aligned}
L_{i}(\Delta) & =\sum_{k=1}^{3} \tau_{k}\left\{\prod_{e=0}^{3} P\left(e_{i}=e \mid \mu_{k}\right)^{1\left[e_{i}=e\right]} \prod_{m^{\prime}=0}^{2} P\left(m_{i}^{\prime}=m \mid \mu_{k}\right)^{1\left[m_{i}=m\right]} \prod_{s=0}^{1} P\left(s^{\prime}=s \mid \mu_{k}\right)^{1\left[s_{i}^{\prime}=s\right]} \times\right. \\
& \left.\times \prod_{t=2}^{8}\left\{\prod_{m=0}^{2} P\left(m_{i t}=m \mid \mu_{k}\right)^{1\left[m_{i t}=m\right]} \prod_{s=0}^{1} P\left(s_{i t}=s \mid \mu_{k}\right)^{1\left[s_{i t}=s\right]}\right\}\right\}
\end{aligned}
$$

where $\Delta$ is the set of parameters. I maximize the product of Equation 15 over all individuals in the sample with respect to $\Delta$.

As noted above, the model is identified by theoretically motivated exclusion restrictions and timing assumptions. Local area tuition and college accessibility variables shift the probability of different education outcomes, but conditional on education, they do not affect other endogenous variables. Age 14 tobacco control policies shift whether an individual is observed to be smoking in 1984 (when individuals were between 19 and 27 years of age), but do not shift subsequent smoking decisions conditional on initial smoking behavior. Lagged county level unemployment rates shift the propensity to relocate, but conditional on location, do not affect future smoking behavior. Furthermore, while not required for identification, per-wave county-level tobacco control policies enter only Equation 14, the per-wave smoking equation. These include state-level packs sales per capita and gross cigarette tax revenue, which capture state-level attitudes towards tobacco. In addition to these exclusion restrictions, technical identification is already guaranteed given the functional form assumptions associated with nonlinear estimation equations.

\section{Results}

Individual parameters are difficult to interpret because of the dynamics of the system, but I present parameter estimates and the associated standard errors from the smoking equation (Equation 14) in Table 3 for three separate specifications of the model. ${ }^{32}$ First, column 1 of Table 3 shows logit coefficients for per-period smoking decisions when the per-period smoking equation is estimated separately from the model and without any treatment of unobserved heterogeneity. Column 2 of Table 3 presents estimates of the jointly estimated system but where the unobserved heterogeneity is not allowed to vary by the initial location at age 14 . Finally, column 3 presents estimates of the preferred specification, jointly estimating all equations together and allowing for unobserved heterogeneity as a function of age 14 location. The coefficient on remote county of residence is significantly attenuated as I move from column 1 to column 3, which reflects the fact that unobserved heterogeneity drives the joint location and smoking behaviors once I allow it to depend on age 14 location. Relative to column 1, where each equation is estimated

\footnotetext{
${ }^{32}$ Estimates of parameters from other equations of the preferred model (corresponding to Column 3 of Table 3 ) are presented in Appendix Tables 3-6.
} 
separately, column three allows the unobserved heterogeneity to be correlated across equations, and the estimated loadings on the unobserved factor are large and significant. Finally, regardless of specification, the coefficient on the annual pack sales per capita in a person's state of residence is large and statistically significant. At the mean metro pack sales per capita, the effect size in column 3 is on the order of the difference between high school and less that high school (i.e., $0.007 * 83=0.581$ ).

\section{Table 3 Goes Here}

To demonstrate the importance of modeling the unobserved heterogeneity, Table 4 presents parameter estimates from the discrete factor approach under the preferred (column 3 of Table 3) specification for each behavior. Subject to the normalization that $\mu_{1}=0$, Table 4 presents the estimated $\mu$ parameters from each equation of the system as well as the probability associated with each discrete mass point and how different locations at age 14 shift the type distribution. For example, the most common estimated type (58.4\%) receives values of $\mu_{2}$ in each equation. Type 2 individuals are significantly more likely to be highly educated and they are significantly less likely to to be observed smoking in 1984 and subsequent waves. ${ }^{33}$

\section{TABle 4 Goes Here}

Next, I demonstrate that the model captures the location specific decline in smoking in the data from Figure 1. To do so, for each of the 4,626 individuals, I replicate their panel 30 times, and for each replicated person, I endow them with a type from the estimated $\mu$ distribution based on their age 14 location. For each subsequent observation of the individual, I endow them with a complete set of draws of the $\epsilon$ terms. Next, I simulate each equation forward, taking care to update the the endogenous location and smoking choices. That is, if a person is simulated to move from a metro to remote county, then the location that enters the next wave's behavioral equations reflects this move, regardless of what happens in the data. Furthermore, under this scenario, the migrant to a remote area is assigned the mean local area characteristics of remote areas in the data. To assess model fit, I attempt to recover the location-specific smoking trends found in the NLSY via a baseline simulation in which all behaviors remain endogenous. Figure 4 shows that the model is able to capture these location-specific smoking trends well.

\section{Figure 4 Goes Here}

\footnotetext{
${ }^{33}$ Appendix Figure A1 presents simulated smoking by type. Although $\mu$ terms enter each equation as intercept shifters, Figure A1 demonstrates that type 3 is associated similar baseline smoking as type 1, but type 3 individuals quit at a much faster rate.
} 
Building off of evidence in Table 4 that demonstrates that selection on unobservables may be an important driver of smoking disparities, Figure 5 presents the distribution of unobserved heterogeneity in 1984 and in 2014 by location. Recall from Table 4 that, based only on unobserved heterogeneity, type 2 individuals are the least likely to be smoking in 1984 and the least likely to be smoking after 1984. Over this period, the fraction of type 2 individuals in remote areas declines by $7.3 \%$ (58.43\% to $54.18 \%)$. As the data are balanced, this reduction reflects a shift in the local area composition of unobserved types. Histograms in Figure 5 are consistent with larger proportional changes in remote areas, as remote areas constitute a small fraction of the sample - migration out of remote areas can significantly change smoking prevalence in remote areas without dramatically changing the type distribution in metro areas.

\section{Figure 5 Goes Here}

I now turn to a series of simulations that isolate mechanisms behind the metro/remote smoking disparity. Figure 6a shows the baseline simulated smoking behavior for those in metro and remote areas, which by 2014 is simulated to be 7.75 percentage points. Figure $6 \mathrm{~b}$ examines the extent to which selection on permanent unobserved heterogeneity generates the disparity in Figure 6a. That figure presents results from a simulation in which, regardless of age 14 location, the permanent unobserved type is assigned according to the estimated metro distribution of unobserved heterogeneity. That is, the proportion in each type are the same across age 14 remote, adjacent, and metro locations, after which smoking behavior and location are simulated forward endogenously. This simulation is possible because of Equation 9, which estimates location specific distributions of unobserved heterogeneity. Because the model allows for endogenous migration between remote and metro areas, many of those "mismatched" types as a result of the baseline type equalization migrate over time, and the 2014 smoking disparity is only $12.3 \%$ (0.068) smaller than in Figure 6a.

Next, results in Figure 6c are from a simulation that returns to the baseline distribution of unobserved heterogeneity but one that restricts migration such that the compositions of local areas are not allowed to change. The gap in smoking in 2014 is reduced by $20.6 \%$ (to 0.062 ), which is a combined effect of a slight increase in metro smoking and a slight reduction in remote smoking. Figure $6 \mathrm{c}$ is consistent with the model presented in Section 2 and Figure 5, in which some smokers move from metro to remote areas and non-smokers move from remote to metro areas. The combination of simulations whose results are presented in Figures $6 \mathrm{~b}$ and $6 \mathrm{c}$ is presented in Figure $6 \mathrm{~d}$. Here, I impose the same equal type distribution restriction as in Figure 6b, but also I do not allow movement across space. The combination of these restrictions reduces the disparity by $62.8 \%$ to (0.029) relative to baseline. Figure $6 \mathrm{~d}$ demonstrates that baseline equalizing unobserved heterogeneity and fixing the composition of this heterogeneity across space explains the majority of the 2014 smoking disparity. 
Finally, Figure 6e reassigns cigarette taxes, gross cigarette tax revenue, and per-capita smoking rates in remote areas to the metro averages in each year. Reassigning remote per-capita smoking rates to the metro averages proxies for a simulation in which, in addition to similar tax laws, the remote attitudes and norms around smoking are set to those in metro areas. By 2014, the metro/remote disparity falls by just 7.3\% (to 0.072), as remote smoking declines only slightly.

\section{Discussion and Conclusion}

Of course, remote populations exhibit, on average, lower incomes, more poverty, lower education, less health insurance, and higher rates of mortality (NC Rural Health Research Program, 2017). For these reasons, we would expect higher rates of smoking, as evidence suggests that each of these is correlated with smoking. However, what is striking is that, at least in the NLSY, smoking initiation in metro areas was just as high as remote areas. In the NLSY cohort, the metro/remote smoking disparity emerges after the smoking initiation phase, ${ }^{34}$ so the selection on unobservables story highlighted in this paper is really a correlation between metro location and the propensity to quit. Yet the results in Section 5 demonstrate that differential tobacco control policies are not the main driver of the smoking disparity between metro and remote residents; instead, the combination of selection on unobserved heterogeneity and migration are significantly more important. Those raised in metro areas are less likely to continue smoking and more likely to remain in metro areas and seek higher education. Individuals mismatched to their location at young ages migrate, but these individuals constitute a small fraction of the sample. The results from this paper demonstrate that individuals less prone to smoke have selected out of remote areas as they age.

The failure in explanatory power of tobacco control policies is not surprising given recent estimates of the tax elasticity of demand for cigarettes. For example, Callison \& Kaestner (2014) estimate a tax elasticity of only -0.05, which implies that a $100 \%$ increase in cigarette taxes only reduces smoking prevalence by $5 \%$. In 2014 , the real local plus state excise tax was only 35\% higher in metro areas relative to remote areas in the NLSY sample. Even assuming a long-run elasticity of double Kaestner and Callison's estimate, a 35\% increase in relative local plus state taxes would only reduce remote smoking by $3.5 \%$ over this time period, which would equate to a less than one percentage point reduction in 2014 remote smoking. ${ }^{35}$ Furthermore, addiction to nicotine, which is ignored in Callison \& Kaestner (2014) may reduce the tax elasticity of demand because the "full" price of smoking remains low. If remote smokers have a longer history of smoking and thus a higher stock of addictive capital, which is consistent with evidence in Figure 1, then the estimates from Callison \& Kaestner (2014) may be even smaller for remote populations, despite

\footnotetext{
${ }^{34}$ The vast majority of smokers start before the age of 30 .

${ }^{35}$ Remote smoking in 2014 is $23.6 \%$ in this sample. A $3.5 \%$ reduction would be a remote smoking prevalence of $22.8 \%$, which is very similar to the reduction simulated in Figure 6e.
} 
the fact that remote populations have lower median income. This evidence suggests that imposing metro tobacco control policies on remote areas may not be an effective policy strategy for reducing cigarette smoking in remote areas.

Another explanation for the smoking disparity may be that as metro individuals enter the workforce, there is more of a social penalty for smoking. Such a mechanism would be consistent with the divergence in metro and remote smoking by 1992, when individuals are between 27 and 35 years of age. Furthermore, metro/remote differences in work culture would be consistent with the causal role of cities, as described by Glaeser \& Mare (2001), whereby peer interactions augment productivity. However, evidence in Figure 2 does not show a meaningful change in smoking behavior after moving to a metro county (and presumably joining the metro workforce). Instead, the combination of who is born into metro areas plus who selects in and out of metro areas over time accounts for more of the disparity.

Remote smoking prevalence may be the greatest contributor to remote health outcome disparities. For example, Case \& Deaton (2016) show that the "deaths of despair" phenomenon, while commonly believed to be a rural problem, is in fact not limited to rural areas. Furthermore, Mack et al. (2017) find that illicit drug use disorders were higher in metropolitan areas, as were drug overdose deaths, and there is little evidence that alcohol use disorders are significantly worse in rural areas. ${ }^{36}$ Despite these facts, rural populations often face significant access challenges conditional on poor health. For example, there are significant barriers to substance abuse treatment in rural communities (Pullen \& Oser, 2016). Furthermore, improving urban/rural health disparities is increasingly difficult given the rapid consolidation and lack of competition in remote provider and payer markets, and the Centers for Medicare and Medicaid Services has recently targeted payment rate formulas for remote hospitals, with the goal of spurring competition in these markets. ${ }^{37}$ In addition to the challenges of providing quality, affordable care in rural settings, providers may also face a less healthy population, in part due to differential rates of smoking.

I acknowledge a number of limitations with this paper. First, the model of migration is simplistic relative to recent structural attempts to capture location decisions (Kennen \& Walker, 2011), and it ignores within region heterogeneity. Similarly, despite that the theory built in Section 2 is based on differential wage offers, the paper lacks a formal labor supply model, which would more richly characterize why individuals move. Second, in many cases, significant time gaps appear in the NLSY because of the lack of information on smoking. Nevertheless, a panel of eight waves over thirty years is still a valuable data resource. Third, the observable heterogeneity in the data are relatively sparse, so it is not surprising that the treatment of unobserved heterogeneity is important. Richer observables would allow the researcher to better pinpoint the selection mechanisms; however, many of the proposed

\footnotetext{
${ }^{36}$ See Figure 8 of https://ruralhealth.und.edu/projects/health-reform-policy-research-center/pdf/2014-rural-urban-chartbookupdate.pdf

${ }^{37}$ https://www.cms.gov/newsroom/press-releases/trump-administration-finalizes-policies-advance-rural-health-and-medicalinnovation
} 
mechanisms arise from variables that are almost never observed in secondary data sources or are difficult to point identify in structural models (e.g., rate of time preference). Finally, the measurement issue of defining "rural" over a long time frame remains challenging. In this paper, I sacrifice measurement error earlier in the panel for precision in later in the panel, although there may be other methods for capturing rural location.

This paper presents a decomposition of the metro/remote smoking disparity over time. I find that tobacco control policies explain little of this disparity; rather, the combination of selection on unobserveables and selected migration explain significantly more. 


\section{References}

American Lung Association. 2012. Cutting Tobacco's Rural Roots. Tobacco Use in Rural Communities. Report. American Lung Association.

Arcidiacono, Peter, Sieg, Holger, \& Sloan, Frank A. 2007. Living Rationally Under the Volcano? An Empirical Analysis of Heavy Drinking and Smoking. International Economic Review, 48(1), 37-65.

Autor, David H. 2019. Work of the Past, Work of the Future. American Economic Association: Papers and Proceeding, 109(5), 1-32.

Becker, Gary, \& Murphy, Kevin. 1988. A Theory of Rational Addiction. Journal of Political Economy, 96(4), $675-700$.

Borjas, George. 1987. Self-selection and the earnings of immigrants. American Economic Review, 77, 531-553.

Borjas, George, \& Trejo, Stephan. 1992. Self-selection and the earnings of immigrants. Journal of Urban Economics, 32, 159-185.

Borjas, George, Kauppinen, Ilpo, \& Poutvaara, Panu. 2018. SELF-SELECTION OF EMIGRANTS: THEORY ANDEVIDENCE ON STOCHASTIC DOMINANCE IN OBSERVABLEAND UNOBSERVABLE CHARACTERISTICS. Economic Journal, February.

Boustan, Leah, Bunten, Devin, \& Hearey, Owen. 2013. URBANIZATION IN THE UNITED STATES, 1800-2000. Working Paper 19041. National Bureau of Economic Research.

Callison, Kevin, \& Kaestner, Robert. 2014. Do Higher Tobacco Taxes Reduce Adult Smoking? New Evidence of the Effect of Recnt Cigarette Tax Increases on Adult Smoking. Economic Inquiry, 52(1), 155-172.

Carneiro, Pedro, Meghir, Costas, \& Parey, Mtthias. 2012. MATERNAL EDUCATION, HOME ENVIRONMENTS, AND THE DEVELOPMENT OF CHILDREN AND ADOLESCENTS. Journal of the European Economic Association, 11(S1), 123-160.

Case, Anne, \& Deaton, Angus. 2015. Rising Morbidity and Mortality in Midlife Among White Non-Hispanic Americans in the 21st Century. Proceedings of the National Academy of Sciences, 112(49), 15078 - 15083.

Case, Anne, \& Deaton, Angus. 2016. REPLY TO SCHMID, SNYDER, AND GELMAN AND AUERBACH: Correlates of the increase in white non-Hispanic midlife mortality in the 21st century. Proceedings of the National Academy of Sciences, 113(7), E818-E819. 
Cepeda-Benito, A., Doogan, N.J., \& et al. 2018. Trend differences in men and women in rural and urban U.S. settings. Preventive Medicine, 117, 69-75.

Chetty, Raj, Hendren, Nathaniel, \& Katz, Lawrence. 2016. The Effects of Exposure to Better Neighborhoods on Children: New Evidence from the Moving to Opportunity Experiment. American Economic Review, 106(4), 855-902.

Coughlin, Lara N., Bonar, Erin E., \& et al. 2019. Changes in urban and rural cigarette smoking and cannabis use from 2007 to 2017 in adults in the United States. Drug and Alcohol Dependence, 205, 107699.

Darden, Michael. 2017. Smoking, Expectations, and Health: A Dynamic Stochastic Model of Lifetime Smoking Behavior. Journal of Political Economy, 125(5), 1485-1522.

Darden, Michael, Gilleskie, Donna, \& Strumpf, Koleman. 2018. Smoking and Mortality: New Evidence from a Long Panel. International Economic Review, 59(3), 1571-1619.

de Walque, Damien. 2010. Education, Information, and Smoking Decisions Evidence from Smoking Histories in the United States, 1940-2000. Journal of Human Resources, 45(3), 877-895.

Docquier, Frederic, \& Rapoport, Hillel. 2012. Globalization, Brain Drain, and Development. Journal of Economic Literature, $\mathbf{5 0}(3), 681-730$.

Doll, R., Peto, R., Boreham, J., Gray, R., \& Sutherland, I. 2004. Mortality in Relation to Smoking: 50 Years' Observations on Male British Doctors. British Medical Journal, 328, 1519-1528.

Doogan, N.J., Roberts, M.E., Stanton, C.A., Keith, D.R., Gaalema, D.E., Kurti, A.N., Redner, R., Cepeda-Benito, A., Bunn, J.Y., Lopez, A.A., \& Higgins, S.T. 2017. A growing geographic disparity: Rural and urban cigarette smoking trends in the United States. Preventive Medicine, 104, 79-85.

Finkelstein, Amy, Gentzkow, Matthew, \& Williams, Heidi. 2019. Place-Based Drivers of Mortality: Evidence from Migration. Working Paper 25975. National Bureau of Economic Research.

Ganong, Peter, \& Shoag, Daniel. 2017. Why Has Regional Income Convergence in the U.S. Declined? Journal of Urban Economics, 102, 76-90.

Gilleskie, Donna, Han, Euna, \& Norton, Edward. 2017. Disentangling the contemporaneous and dynamic effects of human and health capital on wages over the life cycle. Review of Economic Dynamics, 25, 350-383. 
Glaeser, Edward, \& Gottlieb, Joshua. 2009. The Wealth of Cities: Agglomeration Economies and Spatial Equilibrium in the United States. Journal of Economic Literature, 47(4), 983-1028.

Glaeser, Edward, \& Mare, David. 2001. Cities and Skills. Journal of Labor Economics, 19(2), 316-342.

Grossman, Michael. 1972. On the Concept of Health Capital and the Demand for Health. Journal of Political Economy, 80(2), 223-255.

Haenszel, William, Shimkin, Michael, \& Miller, Herman. 1956. A Survey of Tobacco Smoking Patterns in the United States. Public Health Reports, 71(11), 1134-1136.

Hales, Craig, Fryar, Cheryl, \& et al. 2018. Differences in Obesity Prevalence by Demographic Characteristics and Urbanization Level Among Adults in the United States, 2013-2016. Journal of the American Medical Association, $\mathbf{3 1 9}(23), 2419-2429$.

Hall, Jaclyn, Cho, Hee Deok, Maldonado-Molina, Mildred, Geroge, Thomas, Shenkman, Elizabeth, \& Salloum, Ramzi. 2019. Rural-urban disparities in tobacco retail access in the southeastern United States: CVS vs. the dollar stores. Preventive Medicine Reports, 15.

Heckman, James J., \& Singer, Burton. 1984. A Method for Minimizing the Impact of Distributional Assumptions in Econometric Models for Duration Data. Econometrica, 52(2), 271-320.

HHS. 2014. The Health Consequences of Smoking: 50 Years of Progress. A Report of the Surgeon General. Report. U.S. Department of Health and Human Services.

Hillygus, D. Sunshine, McKee, Seth, \& Young, McKenzie. 2017. Reversal of Fortune: The Political Behavior of White Migrants to the South. Presidential Studies Quarterly, 47(2), 354-364.

Ingram, D., \& Franco, S. 2014. 2013 NCHS Urban-Rural Classification Scheme for Counties. Report 166. National Center for Health Statistics.

Jacobs, Jane. 1969. The Economy of Cities. New York: Vintage.

Johnson, Janna, \& Schulhfer-Wohl, Sam. 2019. Changing Patterns of Geographic Mobility and the Labor Market for Young Adults. Journal of Labor Economics, 37(S1), S199-S241.

Kaplan, Greg. 2017. UNDERSTANDING THE LONG-RUN DECLINE IN INTERSTATE MIGRATION. International Economic Review, 58(1), 57-94. 
Keane, Michael, \& Wolpin, Kenneth. 1997. The Career Decisions of Young Men. Journal of Political Economy, $\mathbf{1 0 5}(3), 473-522$.

Kenkel, Donald, Schmeiser, Maximilian, \& Urban, Carly. 2014. Is Smoking Inferior? Evidence from Variation in the Earned Income Tax Credit. Journal of Human Resources, 49(4), 1094-1120.

Kennen, John, \& Walker, James. 2011. THE EFFECT OF EXPECTED INCOME ON INDIVIDUAL MIGRATION DECISIONS. Econometrica, 79(1), 211-251.

Kwok, Viem, \& Leland, Hayne. 1982. An Economic Model of the Brain Drain. American Economic Review, 72(1), 91-100.

Mack, Karin, Jones, Christopher, \& Ballesteros, Michael. 2017. Illicit Drug Use, Illicit Drug Use Disorders, and Drug Overdose Deaths in Metropolitan and Nonmetropolitan Areas-United States. American Journal of Transplantation, $\mathbf{1 7}(12)$.

Miyagiwa, Kaz. 1991. Scale Economies in Education and the Brain Drain Problem. International Economic Review, 32(3), 743-759.

Molloy, Raven, Smith, Christopher, \& Wozniak, Abigail. 2011. Internal Migration in the United States. Journal of Economic Perspectives, 25(2), 1-42.

Mroz, Thomas. 1999. Discrete Factor Approximations in Simultaneous Equation Models: Estimating the Impact of a Dummy Endogenous Variable on a Continuous Outcome. Journal of Econometrics, 92(2), 233-274.

NC Rural Health Research Program. 2017. Rural Health Snapshot. Report. Sheps Center for Health Services Research.

Orzechowski, \& Walker. 2017. The Tax Burden on Tobacco. Historical Compilation. Orzechowski and Walker.

Pullen, Erin, \& Oser, Carrie. 2016. Barriers to Substance Abuse Treatment in Rural and Urban Communities: A Counselor Perspective. Substance Use and Misuse, 49(7).

Roy, A.D. 1951. Some Thoughts on the Distribution of Earnings. Oxford Economic Papers, 3(2), 135-146.

Singh, G., \& Siahpush, M. 2014. Widening Rural-Urban Disparities in Life Expectancy, U.S., 1969-2009. The American Journal of Preventive Medicine, 46, 19-29.

Stillman, Frances, Tanenbaum, Erin, \& et al. 2018. Variations in support for secondhand smoke restrictions across diverse rural regions of the United States. Preventive Medicine, 116, 157-165. 
Winkler, Richelle, \& Johnson, Kenneth. 2016. Moving Toward Integration? Effects of Migration on Ethnoracial Segregation Across the Rural-Urban Continuum. Demography, 53, 1027-1049.

Xu, Xin, Bishop, Ellen, Kennedy, Sara, Simpson, Sean, \& Pechacek, Terry. 2015. Annual Healthcare Spending Attributable to Cigarette Smoking: An Update. American Jouranal of Preventive Medicine, 48(3), 326-333.

Young, Alwyn. 2013. INEQUALITY, THE URBAN-RURAL GAP, AND MIGRATION. Quarterly Journal of Economics, $1727-1785$.

Zahnd, Whitney, James, Aimee, \& et al. 2018. Rural-Urban Differences in Cancer Incidence and Trends in the United States. Cancer Epidemiological Biomarkers Prevention, 21(11), 1265-1274. 


\section{A Tables}

Table 1: Summary Statistics by Location

\begin{tabular}{l|rlrrrl}
\hline \hline & \multicolumn{2}{|c}{ Remote } & Adjacent & \multicolumn{2}{c}{ Metro } \\
& \multicolumn{2}{|c}{$\mathrm{n}=1,906$} & $\mathrm{n}=4,295$ & $\mathrm{n}=30,807$ \\
\hline Smoke & 0.299 & 0.259 & & 0.231 & \\
Age & 40.433 & $(10.802)$ & 39.957 & $(10.792)$ & 40.356 & $(10.650)$ \\
Female & 0.540 & & 0.551 & & 0.555 & \\
Hispanic & 0.042 & 0.091 & 0.187 & \\
African-American & 0.107 & 0.253 & & 0.329 & \\
Education & & & & & & \\
High School & 0.464 & & 0.556 & & 0.415 & \\
Some College & 0.248 & & 0.196 & & 0.250 & \\
College or More & 0.201 & & 0.125 & & 0.256 & \\
AFQT & & & & & & \\
Quartile 2 & 0.195 & & 0.211 & & 0.246 & \\
Quartile 3 & 0.294 & & 0.248 & & 0.238 & \\
Quartile 4 & 0.298 & & 0.195 & & 0.246 & \\
AFQT Missing & 0.022 & & 0.014 & & 0.026 & \\
State Cig. Tax $(\$)$ & 0.837 & $(0.785)$ & 0.748 & $(.725)$ & 0.941 & $(0.852)$ \\
Local Cig. Tax $(\$)$ & 0.002 & $(0.043)$ & 0.006 & $(0.036)$ & 0.127 & $(0.806)$ \\
Gross Cig. Tax Rev. $(\mathrm{m} \$)$ & 295.197 & $(317.530)$ & 350.516 & $(351.552)$ & 460.848 & $(387.917)$ \\
Pack Sales P.Capita & 83.970 & $(30.762)$ & 82.910 & $(31.861)$ & 71.960 & $(32.290)$ \\
\hline
\end{tabular}

Notes: Summary statistics are over the eight waves of the NLSY 1979 Cohort that contain questions on smoking behavior. Location is defined as county of residence merged to 2013 Beale Codes. Beale codes 5, 7, and 9 represent remote counties; 4, 6, and 8 represent adjacent counties; and 1,2,3 represent metro counties. The omitted category of education is less than high school. State cigarette excise taxes are at the state of residence level from Orzechowski \& Walker (2017). Local cigarette tax data are from the American Nonsmokers' Rights Foundation. All dollar figures are reported in 2014 dollars using the consumer price index. 
Table 2: Smoking Regression Results

\begin{tabular}{|c|c|c|c|c|c|c|}
\hline & (1) & $(2)$ & $(3)$ & $(4)$ & $(5)$ & (6) \\
\hline & \multicolumn{6}{|c|}{ Mean of Metro Smoking in $1984=0.395$} \\
\hline \multirow[t]{2}{*}{$\alpha_{2,1984}$} & -0.013 & -0.014 & -0.019 & -0.040 & -0.039 & $-0.063^{* *}$ \\
\hline & $(0.032)$ & $(0.032)$ & $(0.032)$ & $(0.031)$ & $(0.031)$ & $(0.027)$ \\
\hline \multirow[t]{2}{*}{$\alpha_{2,1992}$} & $0.080^{* *}$ & $0.080^{* *}$ & $0.074^{* *}$ & 0.042 & 0.042 & $0.067^{* * *}$ \\
\hline & $(0.033)$ & $(0.033)$ & $(0.033)$ & $(0.032)$ & $(0.032)$ & $(0.029)$ \\
\hline \multirow[t]{2}{*}{$\alpha_{2,1994}$} & $0.099^{* * *}$ & $0.099 * * *$ & $0.092^{* * *}$ & $0.064^{* *}$ & 0.050 & $0.082^{* * *}$ \\
\hline & $(0.032)$ & $(0.033)$ & $(0.033)$ & $(0.032)$ & $(0.032)$ & $(0.027)$ \\
\hline \multirow[t]{2}{*}{$\alpha_{2,1998}$} & $0.072^{* *}$ & $0.072^{* *}$ & $0.066^{* *}$ & 0.039 & 0.040 & $0.073^{* *}$ \\
\hline & $(0.031)$ & $(0.031)$ & $(0.032)$ & $(0.031)$ & $(0.031)$ & $(0.028)$ \\
\hline \multirow[t]{2}{*}{$\alpha_{2,2008}$} & $0.069^{* *}$ & $0.069 * *$ & $0.063^{* *}$ & 0.035 & 0.037 & $0.062^{* *}$ \\
\hline & $(0.029)$ & $(0.029)$ & $(0.029)$ & $(0.028)$ & $(0.028)$ & $(0.030)$ \\
\hline \multirow{2}{*}{$\alpha_{2,2010}$} & $0.074^{* * *}$ & $0.073^{* *}$ & $0.067^{* *}$ & 0.039 & 0.039 & $0.052^{*}$ \\
\hline & $(0.029)$ & $(0.029)$ & $(0.029)$ & $(0.028)$ & $(0.028)$ & $(0.029)$ \\
\hline \multirow[t]{2}{*}{$\alpha_{2,2012}$} & $0.076^{* * *}$ & $0.076^{* * *}$ & $0.070 * *$ & 0.041 & 0.042 & $0.062^{* *}$ \\
\hline & $(0.028)$ & $(0.028)$ & $(0.028)$ & $(0.028)$ & $(0.027)$ & $(0.029)$ \\
\hline \multirow[t]{2}{*}{$\alpha_{2,2014}$} & $0.092^{* * *}$ & $0.092^{* * *}$ & $0.086^{* *}$ & $0.061^{* *}$ & $0.062^{*}$ & $0.074^{* *}$ \\
\hline & $(0.028)$ & $(0.028)$ & $(0.028)$ & $(0.027)$ & $(0.027)$ & $(0.031)$ \\
\hline \multirow[t]{6}{*}{ Controls } & None & Age & Age & Age & Age & Age \\
\hline & & Gender & Gender & Gender & Gender & \\
\hline & & & Race & Race & Race & \\
\hline & & & & Education & Education & \\
\hline & & & & & AFQT & \\
\hline & & & & & TCP & TCP \\
\hline Ind. FE & No & No & No & No & No & Yes \\
\hline
\end{tabular}

Notes: Regression coefficients from a balanced NLSY 1979 sample. Reported coefficients are coefficient estimates on the interactions between year dummies and an indicator for whether the person lives in a remote area. All models include year dummies and year dummies interacted with adjacent residence. The omitted category is metro residence in 1984. Adjacent and remote binary variables correspond to an individual's county of residence at the time of interview. Standard errors clustered at the individual level are presented in parentheses. ${ }^{*} p<0.1,{ }^{* *} p<0.05 * * *$ $p<0.01 . \mathrm{n}=37,008$ in all regressions. 
Table 3: Per-Period Smoking Behavior 1992-2014

\begin{tabular}{|c|c|c|c|c|c|c|}
\hline \multirow{2}{*}{ Age } & \multicolumn{2}{|c|}{ Base } & \multicolumn{2}{|c|}{ System } & \multicolumn{2}{|c|}{ System + IC } \\
\hline & -0.036 & $(0.007)^{* * *}$ & -0.045 & $(0.010)^{* * *}$ & -0.045 & $(0.011)^{* * *}$ \\
\hline Female & -0.042 & $(0.039)$ & -0.144 & $(0.085)^{*}$ & -0.144 & $(0.077)^{*}$ \\
\hline Hispanic & -0.409 & $(0.062)^{* * *}$ & -1.128 & $(0.133)^{* * *}$ & -1.117 & $(0.121)^{* * *}$ \\
\hline African-American & -0.085 & $(0.051)^{*}$ & -0.432 & $(0.099)^{* * *}$ & -0.418 & $(0.097)^{* * *}$ \\
\hline \multicolumn{7}{|l|}{$\mathrm{AFQT}$} \\
\hline Quartile 2 & 0.130 & $(0.056)^{* *}$ & 0.067 & $(0.119)$ & 0.071 & $(0.118)$ \\
\hline Quartile 3 & 0.078 & $(0.062)$ & -0.205 & $(0.142)$ & -0.191 & $(0.131)$ \\
\hline Quartile 4 & -0.114 & $(0.074)$ & -0.955 & $(0.177)^{* * *}$ & -0.947 & $(0.164)^{* * *}$ \\
\hline AFQT Missing & 0.123 & $(0.126)$ & 0.306 & $(0.230)$ & 0.298 & $(0.288)$ \\
\hline \multicolumn{7}{|l|}{ Education } \\
\hline High School & -0.473 & $(0.066)^{* * *}$ & -0.538 & $(0.154)^{* * *}$ & -0.547 & $(0.145)^{* * *}$ \\
\hline Some College & -0.715 & $(0.076)^{* * *}$ & -0.110 & $(0.210)$ & -0.127 & $(0.165)$ \\
\hline College or More & -1.362 & $(0.088)^{* * *}$ & -1.557 & $(0.262)^{* * *}$ & -1.577 & $(0.206)^{* * *}$ \\
\hline Lagged Smoking & 3.670 & $(0.039)^{* * *}$ & 1.362 & $(0.058)^{* * *}$ & 1.362 & $(0.056)^{* * *}$ \\
\hline State Cigarette Tax & 0.170 & $(0.094)^{*}$ & 0.035 & $(0.140)$ & 0.027 & $(0.132)$ \\
\hline Local Area Cigarette Tax & 0.063 & $(0.077)$ & 0.110 & $(0.101)$ & 0.109 & $(0.135)$ \\
\hline State Cigarette Tax Squared & -0.029 & $(0.021)$ & -0.014 & $(0.029)$ & -0.012 & $(0.029)$ \\
\hline Local Area Cigarette Tax Squared & -0.009 & $(0.009)$ & -0.012 & $(0.011)$ & -0.012 & $(0.016)$ \\
\hline Pack Sales P.Capita & 0.006 & $(0.001)^{* * *}$ & 0.007 & $(0.002)^{* * *}$ & 0.007 & $(0.002)^{* * *}$ \\
\hline Gross Cig. Tax Rev. & 0.000 & $(0.000)$ & 0.000 & $(0.000)$ & 0.000 & $(0.000)$ \\
\hline Adjacent & -0.110 & $(0.060)^{* *}$ & -0.142 & $(0.138)$ & -0.143 & $(0.124)$ \\
\hline Remote & 0.170 & $(0.084)^{* *}$ & 0.104 & $(0.162)$ & 0.040 & $(0.165)$ \\
\hline Linear Trend & 0.173 & $(0.029)^{* * *}$ & 0.027 & $(0.039)$ & 0.025 & $(0.044)$ \\
\hline Constant & -2.018 & $(0.257)^{* * *}$ & 3.495 & $(0.429)^{* * *}$ & 3.504 & $(0.430)^{* * *}$ \\
\hline \multicolumn{7}{|l|}{ Unobserved Heterogeneity } \\
\hline$\mu_{1}$ & & & 0.000 & . & 0.000 & . \\
\hline$\mu_{2}$ & & & -6.850 & $(0.207)^{* * *}$ & -6.852 & $(0.208)^{* * *}$ \\
\hline$\mu_{3}$ & & & -2.582 & $(0.094)^{* * *}$ & -2.584 & $(0.085)^{* * *}$ \\
\hline
\end{tabular}

Notes: Coefficients and standard errors from the dynamic system of equations are estimated jointly with parameters that dictate other behaviors and outcomes. The dependent variable is whether an individual smokes cigarettes in each wave between years 1992 and 2014. Column 1 presents estimates when estimating the smoking logit equation separately, outside of the system, and without unobserved heterogeneity. Column 2 presents estimates of the smoking logit when estimated jointly with other equations, but where the unobserved heterogeneity is not allowed to depend on age 14 location. Column 3 presents estimates when the unobserved heterogeneity is allowed to depend on age 14 location and the smoking logit is estimated jointly. The log-likelihood function value from the system in column 3 is $-22740.981 .{ }^{*} p<0.1,{ }^{* *} p<0.05$ $* * * p<0.01 . \mathrm{n}=37,008$. 
Table 4: Unobserved Heterogeneity Estimates

\begin{tabular}{|c|c|c|c|c|c|c|c|c|c|c|}
\hline & \multicolumn{3}{|c|}{$p\left(e_{i}=e\right)$} & \multicolumn{2}{|c|}{$p\left(m_{i}^{\prime}=m^{\prime}\right)$} & \multirow{2}{*}{$\begin{array}{l}P\left(s_{i}^{\prime}=1\right) \\
\text { Smoking }\end{array}$} & \multicolumn{2}{|c|}{$p\left(m_{i t}=m\right)$} & \multicolumn{2}{|l|}{$P\left(s_{i t}=1\right)$} \\
\hline & HS & $\mathrm{SC}$ & MTCO & Adjacent & Remote & & Adjacent & Remote & Smoking & Probability \\
\hline$\mu_{1}$ & 0.000 & 0.000 & 0.000 & 0.000 & 0.000 & 0.000 & 0.000 & 0.000 & 0.000 & 0.140 \\
\hline$\mu_{2}$ & $\begin{array}{l}0.850^{* * *} \\
(0.229)\end{array}$ & $\begin{array}{l}1.802^{* * *} \\
(0.269)\end{array}$ & $\begin{array}{l}2.037^{* * *} \\
(0.290)\end{array}$ & $\begin{array}{l}-0.146 \\
(0.240)\end{array}$ & $\begin{array}{l}-0.197 \\
(0.313)\end{array}$ & $\begin{array}{l}-4.547^{* * *} \\
(0.203)\end{array}$ & $\begin{array}{l}0.121 \\
(0.191)\end{array}$ & $\begin{array}{l}-0.128 \\
(0.279)\end{array}$ & $\begin{array}{l}-6.852^{* * *} \\
(0.208)\end{array}$ & 0.584 \\
\hline$\mu_{3}$ & $\begin{array}{l}-0.194 \\
(0.238) \\
\end{array}$ & $\begin{array}{l}0.311 \\
(0.287) \\
\end{array}$ & $\begin{array}{l}0.408 \\
(0.310) \\
\end{array}$ & $\begin{array}{c}-0.490^{*} \\
(0.304)\end{array}$ & $\begin{array}{c}-0.635^{*} \\
(0.390)\end{array}$ & $\begin{array}{l}-1.554^{* * *} \\
(0.215)\end{array}$ & $\begin{array}{l}0.078 \\
(0.176)\end{array}$ & $\begin{array}{l}-0.158 \\
(0.258)\end{array}$ & $\begin{array}{l}-2.584^{* * *} \\
(0.085)\end{array}$ & 0.276 \\
\hline
\end{tabular}

Notes: The table presents estimates of the distribution of unobserved heterogeneity from the dynamic system of equations. Subject to the normalization that $\mu_{1}=0$ in all equations, estimates of each mass point in each location are given, with standard errors in parentheses. The last column gives the estimated proportion of the sample following each type. Estimates of $\psi_{0}, \psi_{1}$, and $\psi_{2}$ are $-0.004,-0.302,-1.455$ for $\mu_{2}$ and $-0.198,-0.245$, and 0.717 for $\mu_{3}$. Only the constants are statistically significant. ${ }^{*} p<0.1,{ }^{* *} p<0.05 * * * p<0.01 . \mathrm{n}=37,008$ in all regressions. 


\section{B Figures}

Figure 1: Trends in Smoking Behavior and Real Cigarette Taxes

a. Metro vs. Nonmetro Smoking Behavior

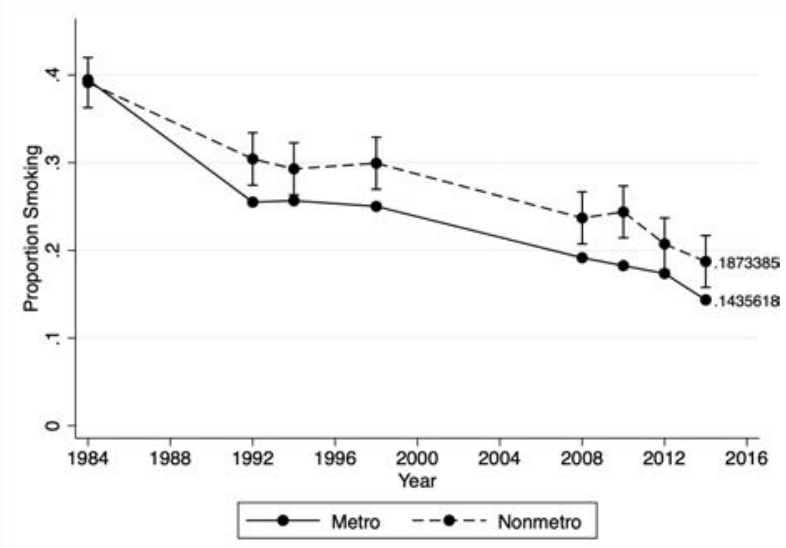

c. Metro and Nonmetro Total Real Cig. Tax

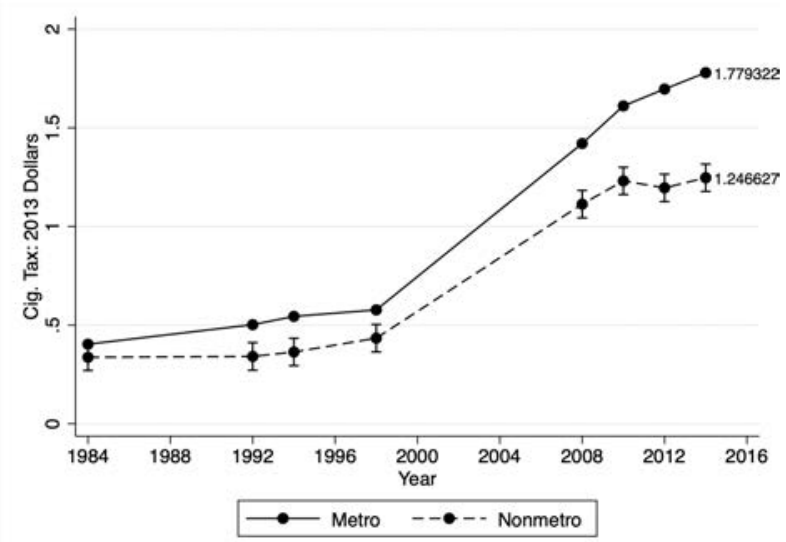

b. Metro, Adjacent, and Remote Smoking

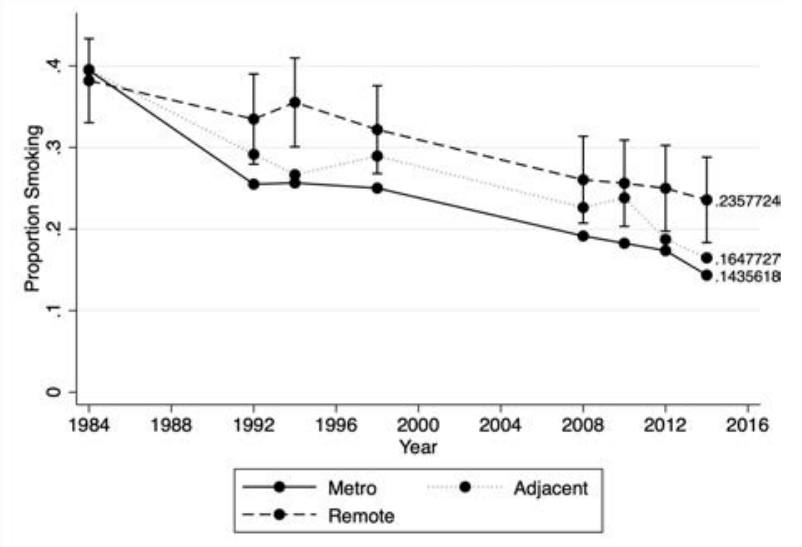

d. Metro, Adjacent, and Remote Total Real Cig. Tax

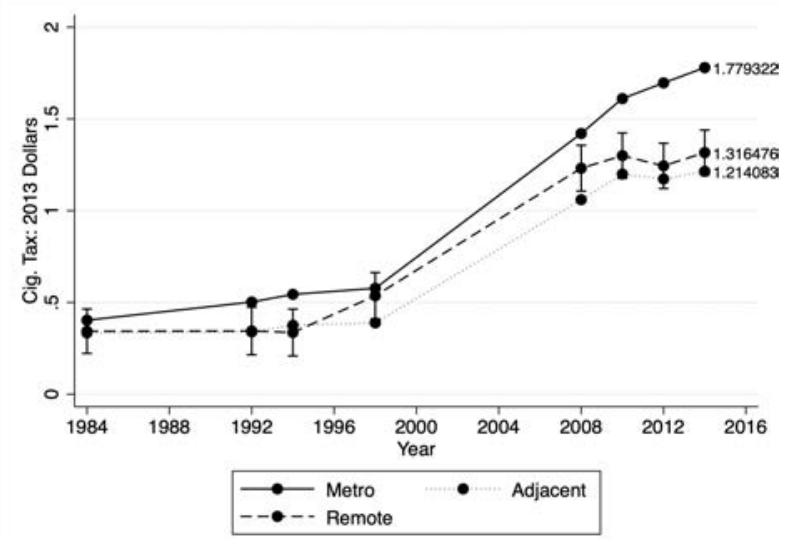

Notes: Figures 1a and 1b present the predicted smoking probability from a linear probability model of whether an individual smokes cigarettes as a function of year dummies and their interaction with location. Figures 1c and 1d present results from a similar model of the real state plus local cigarette tax in 2014 dollars. Brackets indicate the 95\% confidence interval on differential trends relative to the metro trend. In Figure 1a., the p-value on the F-test for differential year parameters by remote counties is 0.010 . The sample includes 37,008 person/year observations, of whom $83.2 \%$ live in metro counties, $11.6 \%$ live in adjacent counties, and $5.2 \%$ live in remote counties. 
Figure 2: Event Studies

a. Interstate Migration

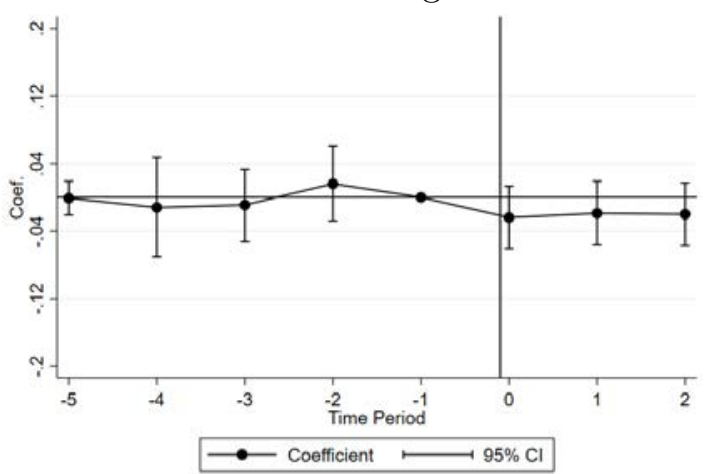

c. Metro to Remote Migration

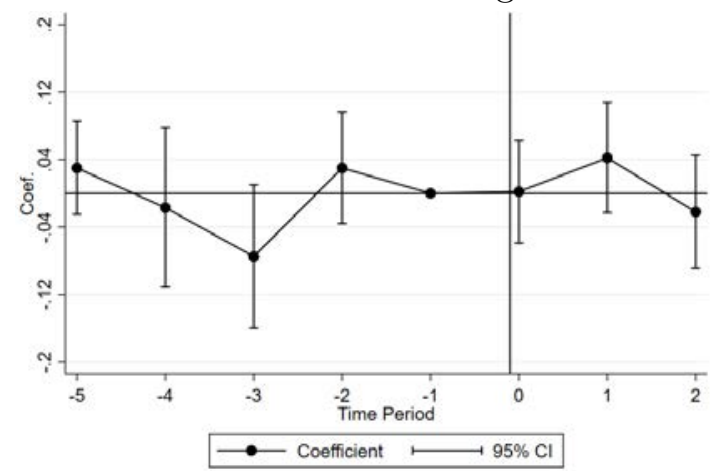

b. Inter-County Migration

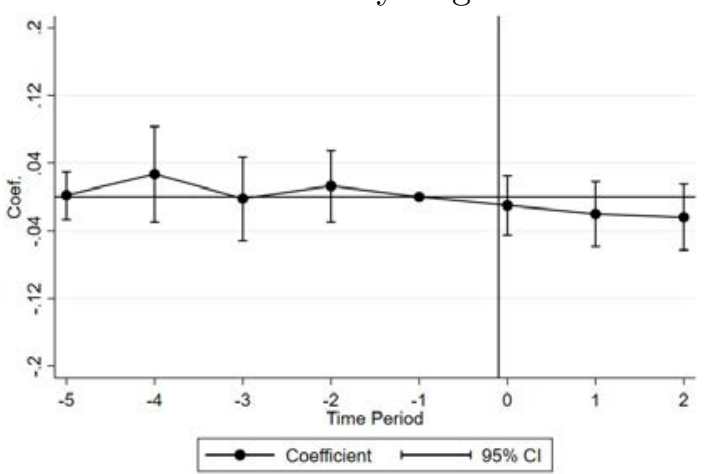

d. Remote to Metro Migration

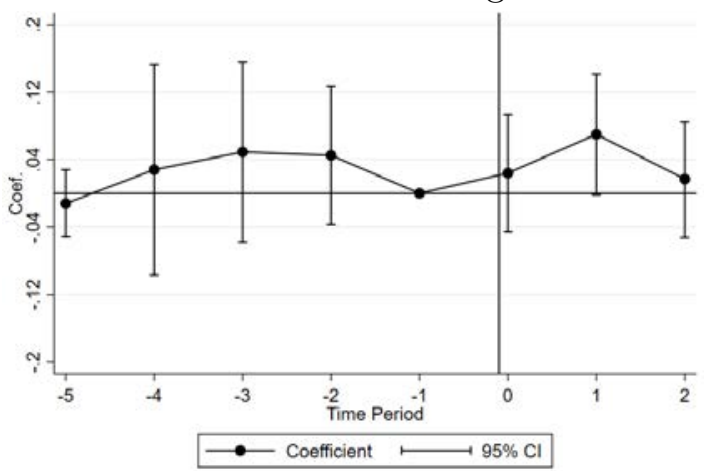

Notes: Each figure presents results from Equation 8 for different types of migration. Brackets represent 95\% confidence intervals. Each set of estimates are from a regression model that includes controls for year dummies, individual fixed effects, and time-varying exogenous variables. The coefficient in period -1 , the period just prior to migration, is normalized to 0 . $n=37,008$ in all regressions. 
Figure 3: Model Timeline

\begin{tabular}{|c|c|c|c|}
\hline Local Edu. & Variables & Smoking & Smoking \\
\hline Year $\in[197$ & $4-1982]$ & Location & Location \\
\hline Age $=$ & & Year $=1992$ & Year $=2014$ \\
\hline Age $=14$ & Year & & \\
\hline Year $\in[1971-1979]$ & Initial $\mathrm{C}$ & & \\
\hline$\mu_{i}=\mathrm{f}($ Location $)$ & Lo & & \\
\hline Local Tobacco Variables & $\mathrm{Sn}$ & & \\
\hline & Edı & & \\
\hline
\end{tabular}

Notes: Time line that documents how data from the NLSY cohort map to the system of equations. 
Figure 4: Model Fit: Smoking Behavior by Location

a. Metro Smoking Behavior

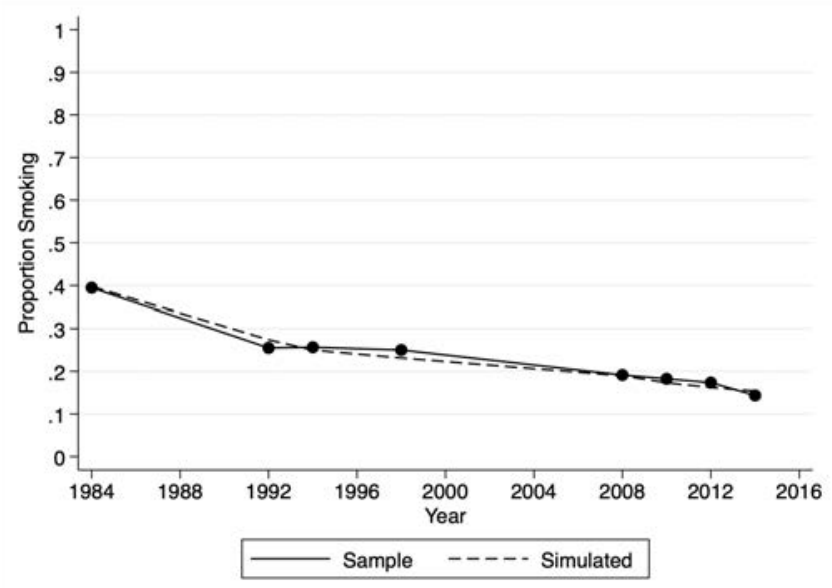

c. Remote Smoking Behavior

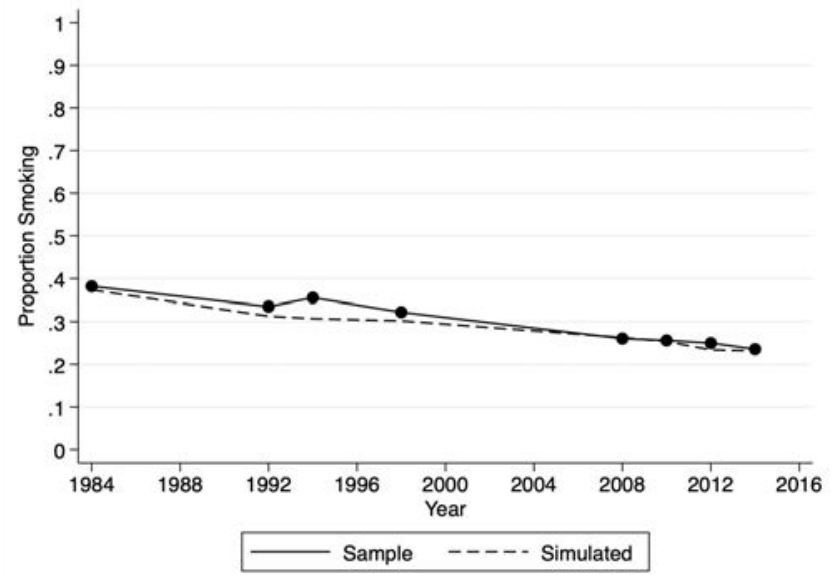

b. Adjacent Smoking Behavior

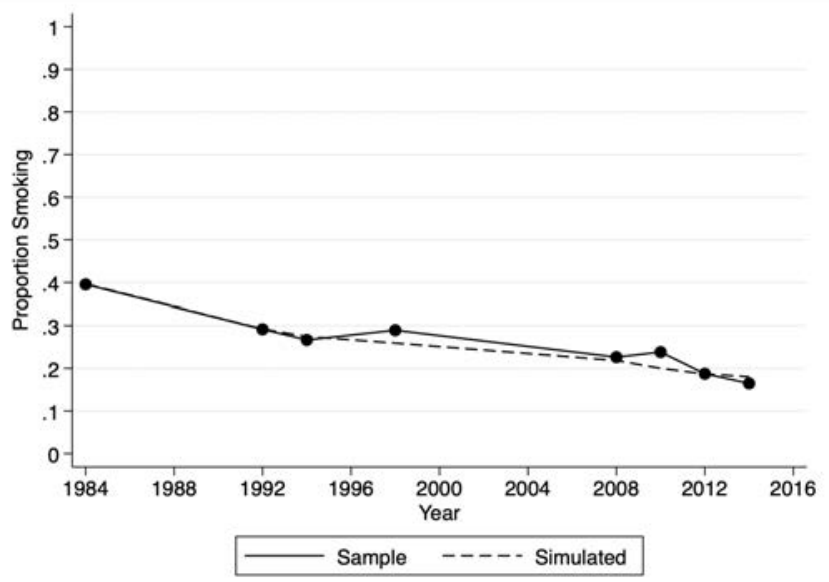

Notes: Each figure presents results from the baseline simulation of the estimated dynamic model relative to sample data. 
Figure 5: Type Distribution by Year and Location

a. Remote Type Distribution

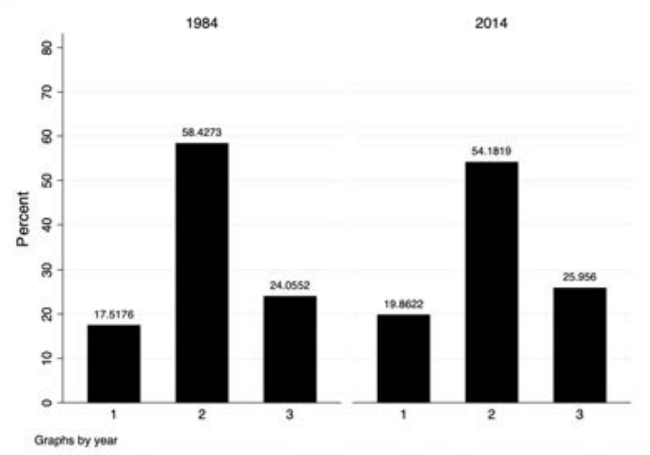

c. Metro Type Distribution

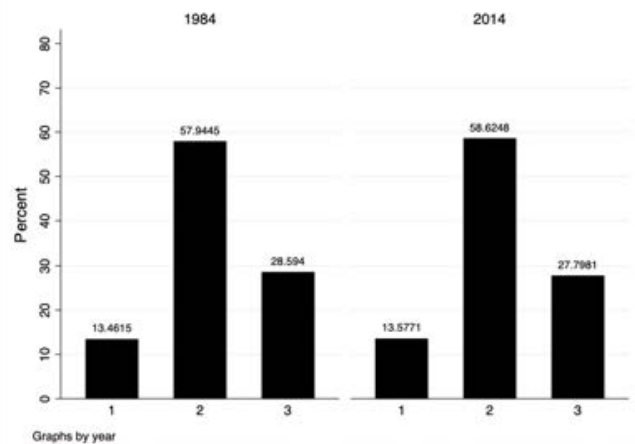

Notes: Each figure presents the estimated unobserved type distribution by year in remote (top panel) and metro (bottom panel). b. Adjacent Type Distribution

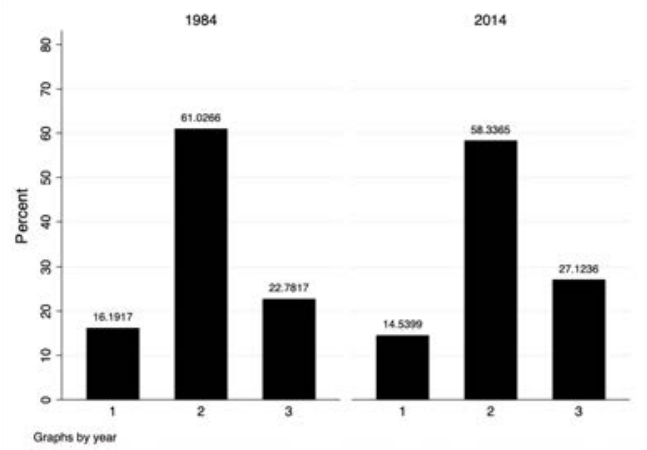


Figure 6: Simulations

a. Simulation: Baseline

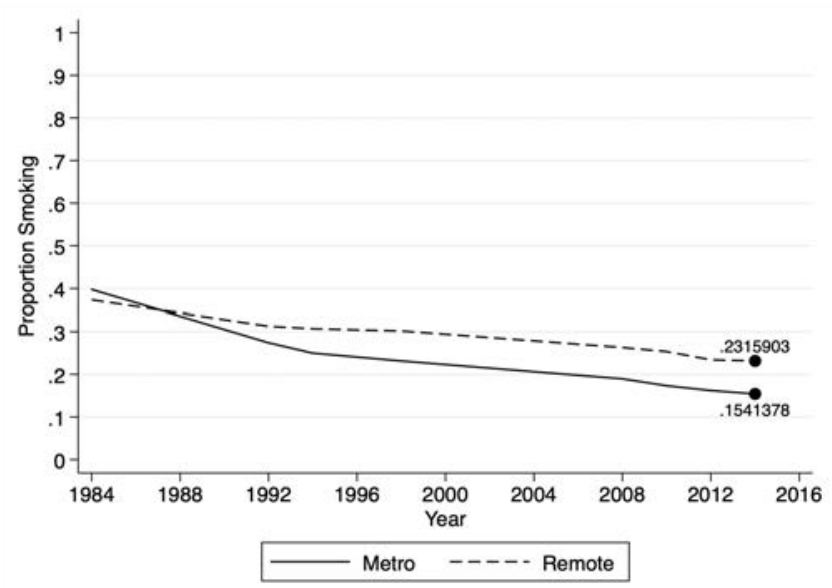

c. Simulation: No Migration

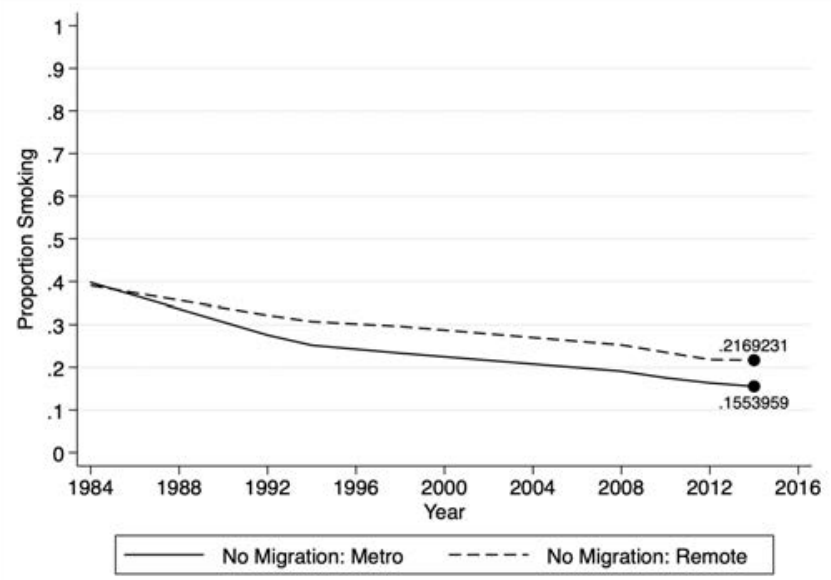

e. Simulation: Metro Taxes

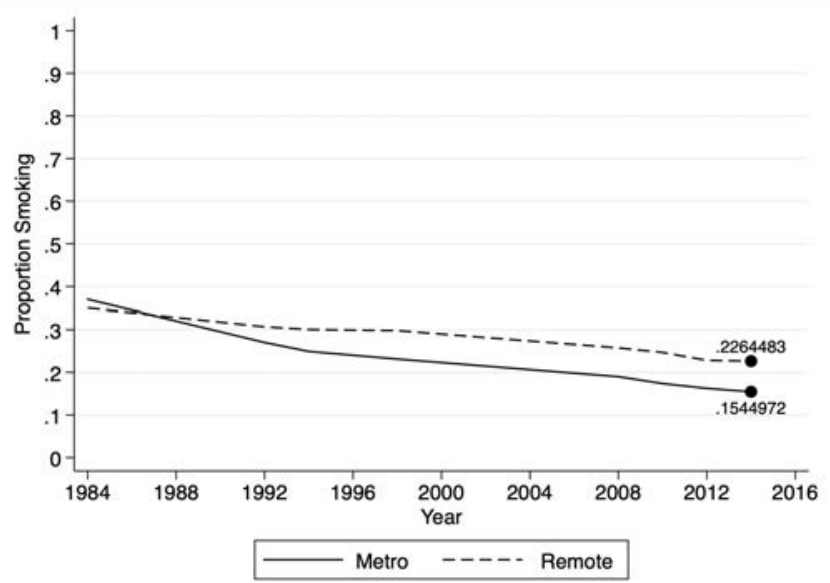

c.

Notes: Each figure presents results from a simulation of the estimated dynamic model under different counterfactuals. b. Simulation: Equalized Type Distribution

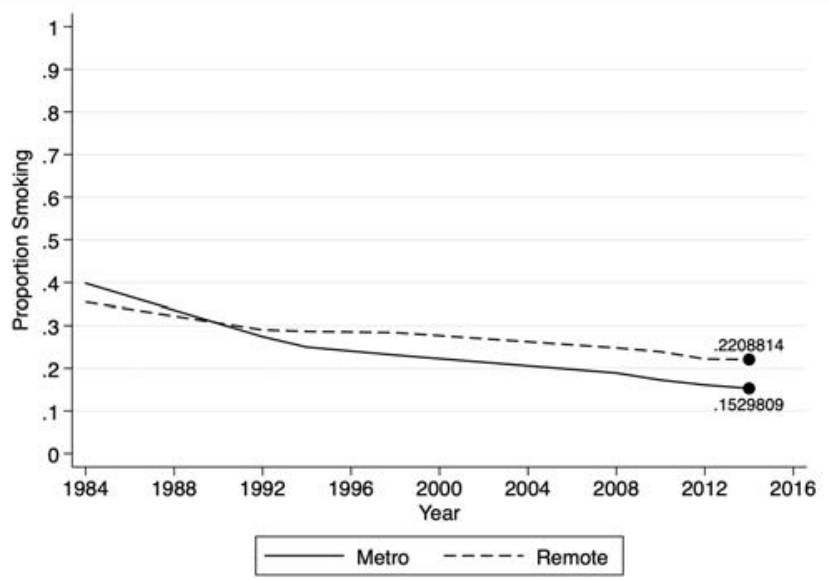

d. Simulation: Equalized Types + No Migration

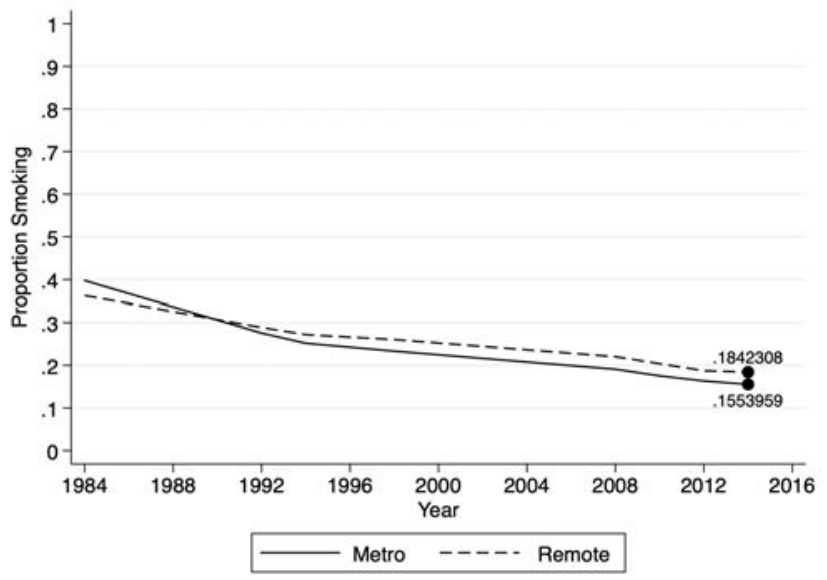

